MA-M 609 
HARVARD UNIVERSITY

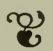

Library of the Museum of

Comparative Zoology 




$$
31,396
$$

LELAND STANFORD JUNIOR UNIYERSITY PUFLIAMTIONS UNIVERSITY SERIES

\section{THE HEMOLYMPH NODES OF THE SHEEP}

STUDIES ON HEMOLYMPH NODES I.

A. W. MEYER

FROM THE

DIVISION OF ANATOMY

DEPARTMENT OF MEDICINE

STANFORD UNIVERSITY 


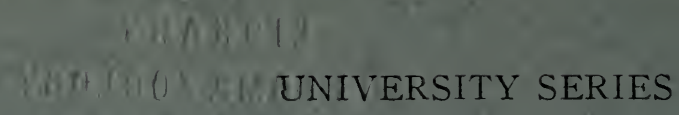

Inheritance in Silkworms, I. Vernon Lyman Kellogg, Professor of Entomology. 89 pp., 4 plates. I908. Price \$I.00.

The Opisthobranchiate Mollusca of the Branner-Agassiz Expedition to Brazil. Frank Mace McFarland, Professor of Histology. I05 pp., I9 plates. 1909. Price, \$1.00.

A Study of the Normal Constituents of the Potable Water of the San Francisco Peninsula. John Pearce Mitchell, Assistant Professor of Chemistry. 70 pp., I map. I9Io. Price, $50 \mathrm{c}$.

Synopsis of the True Crabs (Brachyura) of Monterey Bay, CaliFoRnIA. Frank Walter Weymouth. 64 pp., I4 plates. I9Io. Price, 5oc.

The Osteology of Certain Scombroid Fishes. Edwin Chapin Starks, Assistant Professor of Zoology. 49 pp., 2 plates, I text figure. I9II. Price, $50 \mathrm{c}$.

A Physical Theory of Electrification. Fernando Sanford, Professor of Physics. 69 pp., 2 plates. I9I r. Price, $50 c$.

The Matzke Memorial Volume. Papers by John Ernst Matzke, late Professor of Romanic Languages, and Thirteen Colleagues. I62 $_{2}$ pp. I9Ir. Price, \$r.oo,

Das Historische Präsens in der Älteren Deutschen Sprache. Bruno Boezinger, Assistant Professor of Germanic Languages. 91 pp. I912. Price, 50c.

The Effect of a Strictly Vegetable Diet on the Spontaneous Activity, the Rate of Growth, ANd the Longevity of the Albino Rat. James Rollin Slonaker, Assistant Professor of Physiology. 36 pp., I plate, I 5 text figures. I9I2. Price, $50 c$. Catalogue de Tous les Livres de Feu M. Chapelain. (Bibliothèque Nationale, Fonds Français, Nouv. Acq., No. 318.) Colbert Searles, Associate Professor of Romanic Languages. Ir9 pp., 2 plates. rgr2. Price, $75 \mathrm{c}$.

The Dudley Memorial Volume. Papers by William Russel Dudley, late Professor of Botany, and Several Colleagues. I37 pp., I2 text figures, 9 plates. I9I3. Price, \$1.oo.

The Fishes of the Stanford Expedition to Brazil. Edwin Chapin Starks, Assistant Professor of Zoology. 77 pp., I 5 plates. I9i 3. Price, $75 \mathrm{c}$. 
LELAND STANFORD JUNIOR UNIVERSITY PUBLICATIONS UNIVERSITY SERIES

\title{
THE HEMOLYMPH NODES OF THE SHEEP
}

STUDies ON HEMOLYMPH NODES I.

\author{
A. W. MEYER \\ FROM THE \\ DIVISION OF ANATOMY \\ DEPARTMENT OF MEDICINE \\ STANFORD UNIVERSITY
}

STANFORD UNIVERSITY, CALIFORNIA

PUBLISHED BY THE UNIVERSITY

I9I4 


$$
M a-M 609
$$




\section{THE HEMOLYMPH NODES OF THE SHEEP STUDIES ON HEMOLYMPH NODES, I}

\section{CONTENTS.}

Distribution, occurrence and appearance.

Lymphatic and vascular relations.

The microscopic structure.

The cellular content.

The question of mixed nodes.

The genesis of intermediate forms.

Classification.

Functions.

References.

\section{INTRODUCTION}

Although a number of species were investigated, this paper has purposely been limited to the sheep (Ovis aries), in order that a more comprehensive review of large numbers of hemolymph nodes could first be made. For even a slight familiarity with the subject makes it evident. that it is not only necessary to examine many nodes in the different regions of the same animal, but also to examine large numbers in different animals, and perhaps of animals of varying ages as well. Moreover, a very comprehensive comparative study, although probably indispensable for the elucidation of some of the intricate problems of structure, function and development, usually introduces many additional and related problems which tend to obscure the issue regarding a single species. By first subjecting one species to a thorough examination the problem can also be better defined, many conflicting statements can be ignored, and much confusion avoided. It also seemed probable that an initial and careful comprehensive examination of one species would make it possible to decide with some degree of certainty whether, as recently and so often before reiterated, these organs in a given species are true hemolympi nodes or not, and whether a transformation of hemolypmh nodes into hemal or lymphatic nodes takes place. To this, and to some other ques- 
tions, an unusually large collection of material and a series of observations of some magnitude seem to justify a definite, even if not a final or necessarily a conclusive answer.

Although there are many considerations which would seem to suggest that the term hemolymph is a misnomer when applied to these nodes, this designation, which was suggested by Russel and first used by Robertson [24], is retained throughout a part of this article in order not to introduce a discussion of terms at the very beginning. It is necessary to state, however, that the terms peripheral and central sinuses have been rejected altogether, because no one has shown that they are comparable to the corresponding structures of lymph nodes. The only true sinuses of hemolymph nodes are the radicles of the venous system; the venous lacunae of Weidenreich; which structurally are tremendously dilated capillaries, and which form an integral part of the vascular system of the hemolymph node. The so-called peripheral and central sinuses of the hemolymph nodes can much more properly be designated as subcapsular or marginal and central-in the sense of internal only-blood spaces or areas, than as sinuses, since they are neither in direct communication with either the lymphatic or vascular circulations, as a rule.

The sheep was also chosen as the first subject of experiment and inquiry, because almost all investigators of hemolymph nodes had studied them in this animal to a greater or less extent; because the nodes are much more numerous than in any of the other domestic animals studied; and since a convenient, inexpensive, and also an abundant supply of material was afforded by the abattoirs, where an unlimited number of embryos and foetuses of all ages could easily be obtained. In addition, however, the carcasses of several dozen new-born lambs, two lambs of about five weeks old, and two young sheep six to eight months old, received special scrutiny. Besides, several thousand carcasses were examined and many thousands inspected in the abattoirs in various parts of the country. This varied material naturally afforded an excellent opportunity for observations regarding the relation of sex, age, breed, pregnancy, states of health and nutrition, castration, locality, seasonal changes, and hygienic conditions in general, to the occurrence, size, number and position of these "enigmatical structures." Living sheep could also be subjected to close scrutiny, the carcasses inspected later, and a thorough examination made of the viscera, with a view to detecting any, possible compensatory relationship between hemolymph nodes and other organs, in varying conditions of nutrition and of health. 


\section{Distribution, Occurrence and Appearance}

Even a cursory inspection of hundreds of carcasses in the large abattoirs confirmed the statement that the lumbar subvertebral region is the place in which the hemolymph nodes of the sheep are by far the most numerous, and that their occurrence near the renal arteries has been over-emphasized. Since the lumbar region is especially accessible, these nodes were chosen as the object of special study. In all except very fat sheep they lie exposed to view, and can always be recognized as a whole, even if not individually, as hemolymph nodes by the unaided eye. Hardening the tissue containing them in formaline, as stated by Warthin [3I], did not, in my experience, make them any more conspicuous. Moreover, since their conspicuousness in the fresh state is due to the contained blood, any fixing or hardening agent which does not increase the color contrast between fresh blood and the fat in which they lie can, in the nature of things, not make them more conspicuous except in so far as shrinkage of the surrounding tissues makes them more prominent. Neither did formaline help materially in distinguishing very small nodes from punctiform hemorrhages, since it affected both alike, even if not to a like degree.

Even if they be small, a reasonably accurate count of the hemolymph nodes can, however, be made without difficulty in most cases in the fresh state. From careful counts in several dozen carcasses, supplemented by inspection of several thousand more, it was found that in sheep of mixed breeds the number of nodes in the lumbar sub-vertebral region varied from a few to at most fifty or sixty nodes. Although, to be sure, averages can mean little because of the great fluctuations which exist, a fair average number in this region in young sheep, according to my observations, would be twenty to thirty nodes. The total number in the whole animal varied, however, from half a dozen to a hundred and fifty nodes in exceptional cases. Three or four hundred nodes of macroscopic size, as estimated by Robertson [24] and confirmed later by Warthin [34] as an average number, were never found, in the entire body, including the viscera, even in the most exceptional cases. It is possible, to be sure, that there are breeds or conditions which justify the above estimates; but all evidence obtained in mixed breeds of Merino, Shropshire and Southdown-and just sheep-in the East, in the Middle States, and in the West, makes this supposition very improbable.

In foetuses near term, in several dozen new-born and in four lambs four weeks to six months old, for example, in which a careful examination of the fat in all regions was made with the aid of a hand lens, a 
dozen to a few dozen nodes at most were found. In the new-born only from four to six may be present. From the examination of a large number of foetuses the statement that the younger the foetus the fewer the nodes that can be recognized as hemolymph nodes, seems justified; for it is difficult indeed, as a rule, to successfully identify macroscopically any nodes as hemolymph nodes in any region, in foetuses less than three to four months old. Nevertheless, a striking fact is the occurrence of a greater number of hemolymph nodes in lambs and young sheep. In abattoirs, in which occasionally almost a thousand sheep are slaughtered daily, it is quite possible, in spite of customary mechanical osteological conversions of mutton into lamb, to determine-not in individual cases, of course-whether lambs or sheep are being slaughtered, by a cursory inspection of a number of nodes present in the lumbar region alone. Moreover, such a differentiation is especially easy when lambs and sheep have been put into separate pens before slaughtering, thus avoiding a mixing of the individual carcasses. In fact, these differences are sufficiently marked, so that even the butchers are aware of it and not infrequently comment upon the fact. In one instance, for example, in which a lot of six thousand wethers were slaughtered on successive days, two of the butchers spoke of the smaller number of nodes found in "Western" sheep, adding that in the home or "Eastern" sheep more were to be found. Their observations were entirely correct, but their conclusions were faulty, for it was incorrect to infer that locality or castration were the causative factors in this difference. v Schumacher [27] also mentions the fact that they are more common in young sheep. As reported by Weidenreich [37] and Warthin [3I], the belief of butchers that sheep fresh from pasture have more hemolymph nodes, also found confirmation; but this is likely explained by the fact that such animals are usually lambs, or largely lambs or young sheep, rather than by the state of nutrition of the animals; for such an influence of diet would be as remarkable as surprising and unlikely.

No definite grouping of the hemolymph nodes of the sheep was found to exist, although they occur more abundantly in fairly well-defined regions. Besides, in the lumbar sub- and para-vertebral regions they commonly occur in numbers in the para-rectal fat; more rarely near the renal vessels; and sometimes in a more or less complete series extrapleurally in the intercostal spaces immediately lateral to the vertebral column and near the origins of the great vessels, in close proximity to the lymph nodes between the cervical and thoracic portions of the thymus, and in the region of the head thymus adjacent to the para-thymus glands. 
From the latter glands they are indistinguishable in the fresh state, as pointed out by Drummond [5] and as previously reported by the writer. They never were found on the diaphragm as reported by Warthin [34], on the parietes, or in the sub-scapular, axillary or inguinal regions as reported by Meek [ 17 ] in pathological conditions in man, and but seldom and only in very small numbers in the omentum and in the mesentery. The latter fact is in marked contrast to the occurrence of supernumerary spleens in the cat (Felis domestica) and dog (Canis familiaris) as reported elsewhere.* Those found in the thoracic cavity, in the cervical region, and especially in the intercostal spaces, were smaller, more spherical, and less prominent than those in the lumbar region. Moreover, large specimens were seldom found in any of these regions, the grouping was less distinct, and their presence less constant. The occasional intercostal hemolymph nodes not infrequently simulated small subpleural hemorrhages so closely that they could not be distinguished from them in the fresh state, by inspection alone, and they were too small and too flat for puncture injections.

In the cervical region their occurrence is far less constant than in the abdominal and thoracic regions; but they may lie anywhere between the thorax and the base of the skull. Usually one or even several nodes can be found, however, near the bifurcation of the carotid arteries; and it is not improbable that they have been mistaken for and described as para-thyroid glands. In this and in other regions they often lie so close to the blood vessels that Weidenreich's [37] conclusion that they never lie in direct contact with, even if in close proximity to them, is not confirmed; nor can I confirm $\mathrm{v}$ Schumacher's observations that they usually lie near large lymph vessels, except in so far as large lymph vessels are present in the lumbar region. It should be added, however, that identification of these small cervical nodes was not always made by means of injections, but by microscopic examination and from gross appearances. Since, contrary to the statement of White [39], the latter means of identification is not wholly reliable, the above conclusions are open to question as far as the occurrence of nodes in the cervical region is concerned.

No correlation between the size and the number of hemolymph nodes in one region with those in another region, or with the size, number and condition of the lymphatic nodes, or with any other condition, could be established. Neither were they found enlarged in cases of pneumonia, deep jaundice, tuberculosis, or severe infections with Oesophag-

*See appendix, $\mathrm{V}$. 
ostoma columbanum or streptococci. Pregnancy or castration in themselves seemed to have no effect upon them. The same is true of differences in sex, breed, variations in fatness or poor nutrition, the locality from which the sheep were obtained, or recent hygienic conditions under which they were kept. These conclusions confirm Weidenreich's [37] observations in these respects. To be sure, the implication is not that they are never or can never be affected by all or any of these things. In case of the human hemolymph nodes, for example, it will be recalled that Warthin [33] reported a definite relationship between the occurrence of hemolymph nodes and certain blood diseases, and that Meek [I7] also found them present in various pathological conditions in man.

While the above statement gives the usual distribution, individual nodes may, however, occur anywhere in the fat near the viscera, from the base of the skull to the coccyx. Although no thorough examination was made, none were ever seen between the muscles of the extremities, as stated by Crescenzi,* for bovines. No node was found to be constant in position, in size, or in occurrence. The only constant characteristic, aside from questions of structure and function, is their remarkable variability, and their constant occurrence in fat. It is more than likely, however, that the latter fact is without special significance; and, as in the case of the lymphatic nodes, it is probable that this association between hemolymph nodes and fat has been entirely overemphasized, or misinterpreted even, for the regions in which hemolymph nodes occur are those in which fat is normally present in all animals. Besides, a similar association exists between the main vascular, lymphatic and nerve trunks, sympathetic ganglia, and lymphatic nodes, the kidneys, accessory spleens, etc. Besides, many of the pevertebral nodes are not imbedded in fat but can be moved with the overlying peritoneum.

The variations in the size of hemolymph nodes were as great as those in number, the extremes lying between those invisible to the unaided eye and rarely large oval nodes one or two centimeters long. Both the largest and the smallest nodes were found more frequently in the lumbar region, but it must be remembered that this region was examined much more carefully and extensively than any other. In the cervical and thoracic regions they were often quite spherical, and only from two to four millimeters in diameter. The smallest nodes were always more globular, and, as already stated, often simulated punctiform hemorrhages very closely. The larger ones, on the other hand, were generally

${ }^{*}$ Crescenzi, L.: Contributo allo studio dei gangli ematici nei ruminanti. La Clinica Veterinaria. Anno 29, 1906. 
flattened on the sides sustaining the greatest pressure, and resembled lymph nodes somewhat more closely in shape. Occasionally a group of nodes, or a single node, was found, which looked like a mass of beaded blood vessels, the contiguous walls of which had fused. In other cases isolated nodes were found from which a beaded vessel or vessels (figs. I and 2) closely simulating a lymphatic vessel in form, but dilated with blood, could be seen plainly for some distance from the node, as noted by Weidenreich. In still other instances the appearance was that of a blood vessel of somewhat varying calibre, which formed a loop with local thickenings. Pressure upon these nodular areas of the vessels would easily bring about complete collapse in the area of pressure, followed by subsequent refilling with blood. This effect is in marked contrast to the results of pressure upon hemolymph nodes of any size and location, for these could never be reduced appreciably in size even if subjected to strong pressure. Instead of collapsing they would invariably burst. In some cases these nodular complexes were formed by a number of small nodes which lay in close proximity to each other, or had become more or less completely fused. (Figs. 3 and 4.) Further reference will be made to these later.

Since the descriptions of the external appearance of hemolymph nodes found in the literature on the subject are quite adequate, this matter will be discussed here only in a purely incidental way. Intra vitam and not long post-mortem hemolymph nodes usually have the dark color of moderately venous blood. Rarely, however, light cherry red and scarlet nodes are seen. These are generally small, and lie immediately beneath the peritoneum. The prevailing color in fresh carcasses, however, varied from a bright red to dark chocolate, or even dull black. As pointed out by Robertson [24], this variation is probably chiefly due to differences in the degree of post-mortem oxygenation of the blood within the node. That this assumption is correct was shown by the fact that dark-colored nodes quickly turned to a bright red color when exposed to the air, provided of course that access to them was not made too difficult by the presence of a thick overlying layer of fat, or by the drying of the overlying peritoneum and capsule. This change to a bright color upon exposure is greatly accelerated by stripping the peritoneum overlying the node, or, still better, by exposing the node to pure oxygen. That this color change progresses gradually from the exterior to the interior can also be shown by sectioning nodes which have been exposed to the air or oxygen for varying intervals of time. Such sections show that the outer bright-red layer varies in thickness within limits, with the length 
of exposure to oxygen, for example. It was also noticed that in winter the color of nodes in situ on the carcasses was darker than in summer, which difference was evidently due to the fact that the severe cold of an open abattoir in a northern climate retarded the process of spontaneous post-mortem oxygenation, by making the overlying layers more impervious to the oxygen of the air, or by affecting the rate of chemical interchange. Ordinarily the change in color begins immediately after evisceration, and is noticeable at first in the smallest and most exposed node. However, the rate of the change of color is also dependent upon the presence and the thickness of the surrounding layer of blood in the peripheral blood space. That not all nodes change from a venous color when the abdomen is opened to a bright red upon exposure to the air later may, of course, be due to these and to other facts, as well as to variations in thickness of the capsule and the overlying fat. An examination of several hundred carcasses immediately after the abdomen was opened showed that the variations in color are very slight at this time. Very occasionally, however, a small scarlet node is seen among a group of venous-colored ones, which fact can probably be explained by differences in the circulatory conditions within the node. The peculiarly mottled appearance of nodes which often does not become very evident until fixation and hardening, can likewise be explained satisfactorily by peculiarities of structure. In these latter nodes, for example, the peripheral blood space is encroached upon here and there intra vitam, and often so as a result of shrinkage during fixation and hardening, by the lymphatic tissue-usually by follicles-and may hence be completely obliterated at some places. Wherever this occurs a gray patch or streak bordered by a deeper-colored area will be found on the surface. For like reasons the entire absence of the peripheral blood space before or after fixation might give a whole node a grayish color, or if absent over but a part of the node it might result in an appearance which might suggest that one portion has the character of a hemolymph and the other that of a lymph node, or that there are mixed or composite nodes. Besides these factors, still others, to be discussed later, have an important bearing upon the question of external appearance.

Exposure of hemolymph nodes to carbon dioxide, on the contrary, never produced the slightest visible changes in color. Such as were chocolate-colored when exposed to this gas remained so. The same was true if they were of any other shade. But if nodes thus exposed for a short time were still sufficiently fresh, subsequent exposure to oxygen would result in a change to the usual bright-red color of freshly coagu- 
lated blood. Exposure of fresh hemolymph nodes to gaseous hydrogen sulphide in pure or mixed form, or to weak or concentrated solutions of the same in water, in alcohol, and to an ammonia-alcohol mixture containing hydrogen sulphide would, on the contrary, invariably result in a rapid change to an intensely black color. It was also noticed that exposure of cut nodes in water saturated with hydrogen sulphide caused a more rapid change to a deeper black than exposure in a solution of 80 per cent alcohol similarly saturated. Since the latter solution contains much more hydrogen sulphide than the former, it is apparent that the slower and less pronounced color change in nodes immersed in it is probably due to the effect of shrinkage and hardening, and perhaps also to the dehydrating effect of the alcohol. If they were exposed to the action of diluted instead of concentrated gaseous hydrogen sulphide, a very gradual change to green followed that to black, thus giving the nodes a grayish color, as described by Warthin [36]. Furthermore, if the freshly cut surface of a node was thus exposed, these changes were much more rapid, and the green was frequently so deep that it simulated black. Solutions in water of hydrogen sulphide and of the yellow ammonium sulphide, in various concentrations had a similar action. However, if immersion of the nodes in a solution of sulphide, free from oxygen, was complete, no change from black to green took place at all. The black color remained permanent, and was retained in the alcoholic hardening solutions, as well as in all later processes. These facts suggest, of course, that the change from black to green is indeed an oxidation change of some sort; which conclusion is further confirmed by exposure of nodes to pure hydrogen sulphide, with subsequent exposure to pure carbon dioxide or to oxygen. Nodes kept in pure hydrogen sulphide, or subsequently exposed to carbon dioxide, remained black for days.

As in the case of the color changes due to oxygen, the color change due to these pure gases or mixtures of them was a very superficial one, even after prolonged exposure-for six to eighteen hours-to either gaseous hydrogen sulphide or to a solution of the same. Such exposure never resulted in a color change beyond the depth of one or two millimeters, even on the surface of a freshly-cut node. At greater depths into the node the original color was retained, even for twenty-four hours or more, until maceration and putrefactive changes produced the usual results. The same was true regarding the apparently permanent green color which followed the change to black. If fresh nodes or pieces of the same were immersed in 95 per cent alcohol saturated with hydrogen sulphide, they would undergo the usual color changes; but after weeks 
or months of immersion it was found that both the black and the succeeding gray color had completely disappeared, so that the tissue had the customary gray color characteristic of lymph nodes or of lymphatic tissue fixed in pure alcohol. This change in color occurred even if the alcohol, at the time when the tissue had lost the black color which was acquired through exposure to hydrogen sulphide, still contained hydrogen sulphide in considerable quantity. Sometimes the alcoholic solution contained a small quantity of a dull black deposit after the nodes had lost the black color. This deposit or precipitate, which appeared only after weeks of immersion, was finely granular, and quickly sank to the bottom after shaking.

The action of hydrogen sulphide was comparable to that of oxygen, then, in that its penetration was merely a superficial one, though the color change was apparently more rapid in the case of exposure to hydrogen sulphide than to pure oxygen. This was true, both when a change from dark venous to red, or from a sulphide-produced black to a green color, was concerned; and it may be possible, as has been suggested, that the jet-black color of nodes, occasionally found post-mortem in sheep, may be due to the action of hydrogen sulphide formed in decomposition (?) or from other tissue changes.

In writing of the color changes following exposure to hydrogen sulphide, Warthin [36] stated that "The important point is the fact that in the hemolymph nodes there may be such a quantity of iron-containing pigment that these nodes may take up hydrogen sulphide and become grayish or black in color, while the spleen remains unchanged." (The italics are the writer's.) Warthin further stated that the combination of hydrogen sulphide and iron is probably the cause of pseudo-melanosis, and added in a footnote that "The exposure of hemolymph nodes obtained from cattle and sheep produced results exactly like the autopsy findings in the above cases. The nodes quickly became discolored, some becoming uniformly grayish-black or brownish-black, others becoming spotted or streaked. The discoloration thus produced lasted for a longer time than that seen in human autopsy cases." The color changes reported by Warthin have been confirmed only as far as gross appearances are concerned, for frequent microscopical examination of nodes which had turned black spontaneously or upon exposure, never revealed a picture of pseudo-melanosis, nor was a single test for iron in either the ferrous or ferric forms ever positive. But I am well aware that these tests may not be relied upon with certainty, and, moreover, that the iron may be in the organic form and hence nevertheless present. Consequent- 
ly, it might still be true that the change from red to black which is produced by exposure of nodes to hydrogen sulphide, although not directly attributable to, might yet be accompanied by the presence of an excess of iron in hemolymph nodes. Although Warthin's conclusion regarding the excess of iron in hemal nodes relies partly upon these color changes, it is interesting to report that the fresh blood of any animal turns black almost instantly on exposure to hydrogen sulphide. Evidently, then according to Warthin's reasoning the blood of a number of domestic animals must contain more iron even than the hemolymph nodes of these same animals: a conclusion in direct contradiction to that of Warthin. Moreover, it was found that not only the blood, but also the spleen, muscle, liver, blood vessels-in fact any fresh vascular tissue-would undergo identically the same color changes, and do so even more rapidly in some cases than the hemolymph nodes themselves. From these observations it is clear then that the hemolymph nodes very likely undergo these color changes when exposed to hydrogen sulphide, simply because they are very vascular; and not necessarily, as assumed by Warthin, because they contain an excess of inorganic iron. To be sure, Warthin may be correct in assuming that it is an iron compound which produces these changes. That is not denied here. What concerns us is whether or not these color changes necessarily indicate a greater content of iron on the part of the hemolymph nodes. That this is not the case the facts cited seem to establish beyond all question. To be sure, if, as has been claimed, hemolymph nodes are the seat of blood destruction, with resulting decomposition of blood pigment, it is possible, of course, that they do contain a large or even a larger amount of iron; but the above action of hydrogen sulphides is manifestly not a satisfactory criterion. Moreover, in another article Warthin [32] contradictorily enough reported that he found but a slight or no reaction for hemosiderin in hemolymph nodes. The latter observation, which is contradicted by some investigators, agrees entirely with the findings of the writer; and it seems possible, although perhaps not entirely probable, that differences in the freshness of the material may at least in some measure account for these discrepancies. v Schumacher [27] also emphasized the rare and sparse occurrence of pigment in the hemolymph nodes of sheep.

Although there are great variations in the quantity of blood contained in hemolymph nodes, their vascularity, as judged by external appearances, did not seem to be affected by the rate or thoroughness of bleeding during slaughtering. In sheep which were bled slowly from one carotid or jugular only, or in others which were bled rapidly from 
both carotids and jugulars by severing all the ventral soft parts of the neck, the nodes were always found turgescent. If death occurred without bleeding, there was no marked difference save that the veins draining the nodes seemed a trifle fuller, and the color of the nodes a little darker; which latter fact may perhaps be accounted for by defective aeration of the blood during death. This failure of hemolymph nodes to become paler during death by bleeding stands in striking contrast to what is noticed in many lymph nodes. $v$ Schumacher [27] also emphasized the effect of bleeding upon the color of lymph nodes and pointed out that lymph nodes in foetuses in which free bleeding is secured by severing the cord, are always much paler than those in foetuses which are killed without such bleeding. The significance of these differences in behavior between hemolymph and lymph nodes will be discussed in connection with the circulatory condition in the nodes.

Since the vein draining a node is usually dilated with blood, it can frequently be seen without difficulty on inspection. In almost any carcass one or two nodes can be found the veins of which are plainly visible from five to ten centimeters or more from the node, even if the latter is only a few millimeters in size. Anastomoses with the veins from adjacent nodes are quite common. The artery, on the contrary, is not seen on inspection alone, no matter how turgescent or large the node, or how prominent the vein. Pressure upon the nodes generally results in rupture, without visibly dilating the vein or the artery or decreasing the vascularity of the node. This inability to force out the blood by means of external pressure on the nodes was quite puzzling, until the peculiarities of their structure supplied an explanation.

\section{Lymphatic and Vascular Relations}

Lymphatic vessels were never detected or dissected out in the hilus of a hemolymph node however large, although it was often an easy matter to see and find them near a lymphatic node of much smaller size. Frequently lymphatic vessels of varying calibre and conspicuousness could be seen near hemolymph nodes, or even in contact with them; but even in the case of very large nodes no communication was ever noticed between them and the nodes, upon the most careful examination. Hence these observations confirm the conclusion of Weidenreich [37] in this regard and contradict Helly's [II] statement to the effect that lymphatic channels can be seen to enter the hilus of the hemolymph nodes, although not found within the node, and that nodes which lie near large lymphatics contain such vessels. Aside from the difficulty, or impossibility even, 
of seeing a hilus macroscopically in most of these nodes, it is well to remember in this connection that Helly did not state how the lymphatics were identified positively as such. Moreover, small lymphatic channels might be confined wholly to the capsule of the node or its large trabeculae without necessarily establishing any charasteristic connection with the parenchyma of the node itself. Helly's conclusions and observations are largely confirmed, however, by Forgeot [6 and 7] and v Schumacher [27]. The former described nodes in the lumbar region of goats and sheep, and under the pleura and pericardium of cattle, from which blindly-ending lymphatic vessels of varying form extended. In some cases these vessels returned to the neighborhood of the node and were markedly distended with red lymph. The several vessels were found to end blindly independently, or to be joined into a network which surrounded a node the main branches from which formed a common trunk, which also ended blindly. An examination of Forgeot's articles show very clearly, however, that he has included "red" or hermorrhagic lymph nodes, i. e., lymph nodes with erythrocytes in the sinuses, among hemolymph nodes, an error against which $\mathrm{v}$ Schumacher rightly warns, and which has undoubtedly been responsible for much of the confusion. Nevertheless $\mathrm{v}$ Schumacher, who largely accepted and confirmed the conclusions and observations of Helly and Forgeot, basing his conclusions on an examination of adult and embryological material from the sheep, emphasized the fact that hemolymph nodes usually lie in the neighborhood of large lymph vessels, and that branches of the latter frequently extend considerable distances into the capsule without piercing the latter or coming into relation with the marginal sinus. Sometimes such lymphatic vessels were, however, seen to join the sinus, and these nodes $v$ Schumacher excludes from hemolymph nodes, on the opinion of others. Nevertheless $\mathrm{v}$ Schumacher proceeds to state that all manner of transition forms between lymph and hemolymph nodes exist as far as the relation of the lymphatics to the nodes are concerned, and describes nodes with lymphatic vessels in process of obliteration in different places within and without the nodes, much as Helly has done. v Schumacher also came to the conclusion that hemolymph nodes are only rudimentary or undeveloped lymph nodes which have lost their connection with the lymphatic system as a result of the obliteration of the lymphatics at various points. Consequently, according to $\mathrm{v}$ Schumacher, a lymph node may become a hemolymph node by losing its lymphatics, and can again become a lymph node by regaining them. Since these conceptions and conclusions are based partly upon developmental considerations, they will 
be discussed especially in a separate article on this subject; but it may here be noted that the conclusion that a true hemolymph node is merely a lymph node devoid of lymphatic vessels and sinuses, is only possible upon a fundamental misconception of the real character of the vascular circulation of true hemal nodes.

These considerations at once raise the question of the relation between hemolymph nodes and the lymphatic system. In order to determine whether a direct connection exists between them, injection methods seemed to offer the best and perhaps the only positive proof. Since an abundant supply of material could be found in the carcasses of sheep, the abattoir again suggested itself as an especially good field for this work. Hence many hundreds-thousands-of injections were made directly into the nodes upon the fresh carcasses. Occasionally this was within ten minutes or a quarter of an hour after death. The results obtained by means of puncture injections with a hypodermic syringe into the nodes practically undisturbed in situ in the lumbar region, were surprisingly uniform. As node after node on the hanging carcasses was punctured and injected, the invariable result of the injection of a few drops of methylene blue, Prussian blue, India ink, etc., was the almost immediate appearance of the fluid in the vena cava, or occasionally in the common iliac veins. Since the appearance of even a fraction of a drop of the colored solutions or suspensions quickly became evident in the collapsed veins, it was, to be sure, an easy matter to decide between success and failure. To avoid error many hundreds of injections were made into nodes of various sizes, shapes, colors, and positions in the abdominal and thoracic cavities of sheep from a few weeks to four or five years old. By far the greatest number of these injections were made on the lumbar group, however.

v Schumacher, who agreed with Weidenreich and the writer as to the injections of the vein by means of puncture of the node, however, emphasized the fact that he obtained such a result by no means in every case, but only when one of the intra-nodal veins was pierced. In numerous instances $v$ Schumacher found that only the sinuses in the interior of the gland were filled, and whenever the vein leaving the node was injected $\mathrm{v}$ Schumacher says he could always tell by serial sections that a vein in the interior of the gland had been punctured by the needle, so that the injection mass could pass directly into the large collecting veins at the hilus.

I am at a loss to account for $\mathrm{v}$ Schumacher's failure to inject the veins of hemal nodes in practically all cases by means of puncture of the 
node. To be sure, the choice of nodes is of primary importance, and no one can be positive that he has selected a hemal node if he fails to inject the vein or lymphatics. Besides, no one will doubt that a venous radicle must have been penetrated by the needle or its wall penetrated by the injection mass, if the vein leaving the node is filled; but after examining numerous nodes which had been injected by puncture, I must entertain the gravest doubts as to the possibility of determining the exact point of puncture of a venous lacunae. For even the smallest needle or capillary glass tube bears a marked disproportion to the size of the numerous venous radicles in a node. Besides, it would be likely to pierce so many - or none-for most of the hemal nodes are small, as $\mathbf{v}$ Schumacher rightly emphasizes. Hence locating the exact point of puncture of the wall of a particular venous lacuna through which the injection mass is supposed to have entered, must be open to serious error, even if possible. Moreover, veins are not always present within a node; venous lacunae or sinuses take their place frequently.

It was generally very easy to see the injected fluid pass from the hemolymph node to the vena cava, pushing the blood in the vein leaving the node before it. As more fluid was injected, a steady stream, sometimes inter-mixed with blood and bubbles, could be seen passing to the vena cava or the iliac veins. Frequently the injected fluid would pass in a somewhat roundabout way to reach its destination in the large veins; and occasionally it would leave the node in two directions from the same or from different points. Clamping of the vein on its way to the vena cava led to rupture of the node upon further injection, but not to the injection of lymphatics. Anastomosing veins would occasionally become filled with fluid; but several times only did an adjacent or distant node seem to change its color very slightly. For a time this inability to inject one node from another in the fresh hanging carcasses was very puzzling, for it was evident that the veins from several nodes not infrequently joined on their way to the vena cava. Besides, it will be recalled that Weidenreich [37] reported that it was easy to inject a node from a neighboring one. This apparent contradiction of Weidenreich's results was emphasized further by the fact that it was never possible to inject secondarily smaller hemolymph nodes which lay in actual contact with the larger ones, from which the injection was made. This was true, even when it was afterwards found by injection of differently colored fluids from the individual nodes concerned that they were drained by branches of the same vein. Naturally the fact that small veins draining hemolymph nodes are usually full of blood, suggested that the failure to inject one 
node from another probably was mainly due to the presence of blood, and to some condition within the nodes which prevented a re-flow of this blood to the arterial side. Such conditions alone, it seemed, could explain the above facts, for a system of filled tubes could naturally not receive more fluid without further distention of the vessels of the node, or of leakage or rupture. Consequently, the fat in the lumbar region, including the great vessels, containing especially numerous nodes, was excised en masse, as Weidenreich had done. By means of puncture injections of the nodes it was now found a very easy matter to force the injected fluids into adjacent or occasionally distant nodes, even if the flow toward the excised vena cava was unobstructed. Hence Weidenreich's observations were easily confirmed by using similar methods. But these results now required an explanation; for why should there be such difficulty in injecting one node from another with the nodes undisturbed in situ in the carcasses? Although I have no wholly satisfactory explanation, it is probable, it seems to me, that the manipulation incident to excision of the tissue emptied the veins which drained the nodes, sufficiently to permit the injected fluid to enter. Besides, as shown by the many points of leakage when injections were made into nodes contained in excised tissue, the numerous anastomosing veins which are severed during removal of the tissue also gave opportunity for relief of pressure in several directions. Hence the condition of a system of closed tubes partially or totally filled with fluid no longer existed. It is evident, of course, that it is not essential that the vein which drains a node be completely full of blood to prevent the injected fluid from entering the node, or, on the contrary, that it and the node must be completely empty before any injection mass can enter. All that is manifestly necessary is that a sufficient quantity of blood be contained in the main or in the anastomosing veins to completely fill, or perhaps to sufficiently distend, the venous spaces within the node to make further injection impossible. For in case of a small node even a fraction of a drop of blood in advance of the injected fluid might effectually prevent a successful injection, unless the veins and venous spaces within the node are partially or totally empty. Since these conditions probably obtain more or less in excised tissue, it was possible to inject a series of three or four nodes lying in a row from one of their number, with a few drops of fluid. It was also occasionally possible to inject incidentally a network of minute retro-peritoneal veins-not lymphatics-from nodes in the excised tissue; although such a result was never obtained in the many injections made directly into nodes in situ on carcasses. These veins, 
which after being injected formed a network of the greatest delicacy, were so fine that they were barely visible to the unaided eye.

In a large series of puncture injections, it was never possible to inject a lymphatic vessel or a lymph node from a hemolymph node unless the point of the needle pierced the hemolymph node, thus allowing the injected fluid to enter the retro-peritoneal tissues. A series of puncture injections made into the surrounding tissues and body wall proved equally ineffectual for injecting the hemolymph nodes or blindly ending lymphatics. Both lymphatic vessels and lymph nodes, on the contrary, were injected comparatively easily by either of these methods, and injections into lymph nodes always led to the well-known results. The usually characteristically beaded lymphatic channels were instantly apparent, other lymph nodes were injected, and the injected fluid soon ran out of the cut end of the thoracic duct in the cervical region, just as it had previously run out of the vena cava in the thoracic region. Nor did the injection of some unusually large-3-4 $\mathrm{mm}$.- lymphatic channels occasionally seen in the lumbar region, result in the injection of anything but lymph channels and lymph nodes. In three carcasses, for example, especially large lymph channels three to four millimeters in diameter lay superficially among a group of hemolymph nodes in the lumbar region. The injection by puncture of methylene blue into these large lymph vessels, even when the thoracic duct had been clamped and lymph nodes on all sides were injected both peripherally and centrally, resulted negatively, as before, as far as injection of hemolymph nodes is concerned, even when high pressure was used. Hemolymph nodes, on the other hand, were never injected, even if they lay side by side with or directly upon or beneath injected lymph nodes; and not a trace of the injection was ever found in them upon microscopical examination.

The facts just cited, together with others to be considered, prove conclusively, it seems to me, that, as maintained by Weidenreich [38], the circulation of true hemolymph nodes, exclusive of the capsule at least, has no connection whatever with the lymphatic system. They prove further that there probably are no nodes of a mixed type having sinuses common to the vascular and lymphatic systems, and that consequently the word hemolymph is a misnomer when applied to these nodes of the sheep. Since, then, all these so-called hemolymph nodes are solely in direct connection with the vascular system alone, and contain no lymph spaces, the designation of hemal node first used by Clarkson [2] is preferable, and will hence be used in this discussion.

Since these results seemed to indicate that hemal nodes are entirely 
independent of the lymphatic system, injections were also made from the abdominal vena cava and aorta, in order to determine whether the spaces found in hemal nodes are in direct connection with these vessels. Such injections were made on two lambs seven to eight months and four to six weeks old, and six foetuses from four to five months old. Three of these lambs were bled to death. In case of the other lamb and the foetuses, some relief from back pressure due to the contained blood was secured by incision of the vena cava. Injections of filtered carmine and Prussian blue gelatine were made directly into the abdominal portions of these vessels. The carcasses were kept immersed in warm water and a high uniform pressure $(200-250 \mathrm{~mm}$. Hg.) was maintained continuously for a period of one-half to three-fourths of an hour. Besides this, the injection was limited as far as possible to the lumbar region by clamping the main branches of the great vessels. Since the injection mass was thus limited to a small field, the behavior of the hemal and lymphatic nodes could be observed more carefully during the progress of the injection. Although at first it was attempted to mark the site of some of the typical hemal nodes, by transfixing the adjacent tissue with a small pin, the high pressure used on the filtered gelatine caused considerable leakage at the point of puncture, which threatened to obscure the field. Hence this method was abandoned.

Upon completion of the injections, the bodies of the foetuses were cooled, and fixed, in toto, in formaline. In case of the lambs, the whole lower half of the body was likewise preserved, in order to leave the area under observation undisturbed. All nodes were later dissected out by means of a lens when necessary; and cut serially in paraffine. It was found advisable to remove all nodes found in a given area, because of the difficulty, or impossibility even, of distinguishing injected hemal and lymphatic nodes by external appearances.

During the course of the injection it was disappointing to notice how quickly even the smallest lymph nodes, distant often from the place of injection, would quickly change their color due to entrance of the injection mass, while much larger near-by typical-as judged by external appearances-hemal nodes showed no color change whatever. That this apparent failure to inject the great majority of the hemal nodes was not due to a faulty technique, was shown by the fact that the whole carcasses were so well injected, in spite of ligation of the main branches of the great vessels, that even the small parathymus glands had changed their color and were found on microscopic examination to contain much injection mass. 
Before giving a statement of the results obtained by these injections, a rough sketch of the microscopic structure of the more usual hemal nodes seems advisable. In the majority of these nodes, a view of a section made in any plane presents the following well-known appearances. Externally there is a fibrous capsule varying considerably in thickness in the same and in different species, beneath which there usually is found a continuous or, oftener, a discontinuous so-called peripheral sinus, of inconstant width, which generally contains more or less blood and lymphocytes. As a rule, by far the larger area of the node is composed of lymphatic tissue, containing the well-known blood sinuses, or better, blood islands or spaces.*

A definite cortical and medullary portion, or an arrangement of the lymphatic tissue into medullary cords, was never seen. The arteries are inconspicuous as a rule, and the veins frequently still more so. In addition to the inconstant, large central venous spaces in direct connection with veins more or less evident partially collapsed or open spaces, the so-called venous lacunae of Weidenreich may also be present throughout the parenchyma. When evident they are usually best seen near the periphery of the parenchyma, and frequently contain a small number of erythrocytes and lymphocytes, the former often being found in varying states of degeneration. The blood islands and spaces other than the peripheral or subcapsular blood space, and the main arteries, often have a more central position, however; but the veins generally branch soon after entering the node and traverse the peripheral sinus, or better the marginal or subcapsular blood space. Although rarely noticeable throughout the node, the trabeculae are few and small, as a rule. The coarser reticulum is plainly visible under low-power magnification, and is more evident in the partially filled blood spaces, especially in the marginal one. Since this sketch is to serve merely as a basis for a statement of results obtained by injection, a more detailed and accurate statement of structural variations and relations is deferred.

Injections made from the vena cava, and by puncture from a node, always gave a very characteristic and uniform result. No matter how little of the injected fluid gained access to the node, it almost always lay as an exceedingly irregular mass, often of minute breadth, which zig-

*Since the blood islands are usually masses of erythrocytes contained in the lymphatic tissue, rather than empty spaces temporarily devoid of blood, although such undoubtedly occur, the term blood space might preferably be restricted to the empty areas, which once contained blood islands; and since neither of these nor the peripheral sinus are really such, the term sinus had better be restricted to the dilated venous radicles in direct connection with the circulation. 
zagged about, but small amounts of which were but seldom found in the peripheral or central-in the sense of internal-blood islands or blood spaces. (Fig. 2.) However, if the injection was a fairly complete one, the gelatine mass or the India ink was distributed quite uniformly throughout the node, and some of it was rarely found within the follicles; although instead of penetrating these, it usually surrounded them. In some places, the masses of injected material formed an incomplete and a very irregular circuit, parallel and internal to the peripheral blond space, which was, however, always separated from the former by a very thin barrier of lymphatic tissue. In case of injections of India ink by puncture, the resulting picture was always similar to that obtained by injections from the vena cava; but since the puncture injections were generally much completer, a greater amount of injection material was present. In these instances some of it was found in the peripheral blood space (sinus), in some of the blood islands, and not infrequently in some of the follicles as well. These puncture injections, whether made directly into a node or indirectly into an adjacent one, were, of course, also venous injections (figs. 5 and 6). Strangely enough, out of scores of nodes injected from the venous side, only a few showed the injection mass lying in large blood spaces in the center of the node. In two cases of injection by puncture, the India ink also found its way into an artery lying near a vein, wholly outside of a node. In the latter cases it seems likely that the ink entered the outlying artery through accidental puncture of one of its branches within the node, rather than by passing from the larger blood sinuses or lacunae into a capillary or an arteriole and then to the parent trunk. Unfortunately, however, the material at hand does not justify a definite conclusion regarding these rare accidental results.

Carmine gelatine injections from the aorta gave very similar results. (Fig. 7.) If the injection of the node was only a partial one, however-as was usually the case-the injected mass was found mainly in the venous lacunae at the periphery, and to a far less extent near the center of the node. Hence in the case of a complete injection it would be difficult indeed to distinguish an arterial from a venous injection, were it not for the fact that in the former the main arteries and their branches, and frequenly some arterioles and capillaries, are well injected, thus making differentiation comparatively easy. Arterial injections from the aorta also differed from most of the venous injections made by puncture, in the fact that the injection mass seemed to penetrate the filled blood spaces with more difficulty. This result may have been due, however, 
to the differences in pressure and to interference with the architecture of the node by the puncture in case of direct puncture injections, as well as to other things to be discussed presently. Unfortunately, none of the nodes injected from the aorta had a sufficiently definite peripheral (sinus) blood space to afford good evidence regarding its relation to the arteries. That the injection mass could have entered the peripheral (sinus) blood space follows, however, from the fact that the latter always contains more or less blood. Hence both it and the central blood spaces must, to be sure, communicate in some manner with the vascular system, even if not directly with it as a rule, or with the artery.

The most significant result obtained from these injections was that the so-called venous lacunae or radicles could generally be injected from both the vena cava and from the aorta. It is true that these injections were not of equal completeness, and also varied in certain other minor respects; yet the above fact seems to demonstrate conclusively that the venous lacunae, or true venous sinuses of the hemal nodes of the sheep, occupy a position intermediate between the veins and the arteries, and hence bridge a gap between them. However, as already stated, the fact that the blood spaces are more easily injected by puncture than from the aorta, can readily be explained by the fact that higher pressures were undoubtedly used, that a more direct and sudden entrance of the injection mass is effected, that the architecture of the node may be seriously disturbed, and that the needle may happen to stop in the parenchyma, in the case of direct puncture injections. Moreover, in case of injections from the aorta the injection mass, which enters slowly through the artery, can pass directly onward into the wide venous lacunae and large veins, without producing any appreciable back pressure in them, because of the difference in calibre between the arterial capillaries and venous sinuses. Hence the injection is likely to be incomplete. That the injection masses or the pigment, are generally found in the venous lacunae or true sinuses, and not in the blood islands and spaces, is explained by the fact that the former are usually empty spaces, with permanent walls which, although usually in a state of total or partial collapse, are directly connected with the arteries, and hence offer far less obstruction to the entrance of the injection mass than the blood spaces. The latter are traversed by reticulum and are filled with blood which has no easy and free means of escape. Furthermore, the communication between the venous lacunae and blood spaces is, as a rule, only an indirect one.

The great irregularity in shape of the injection masses and the pigments, in both arterial and venous injections, somewhat suggested extravasations. This was probably due to the necessarily incomplete nature of 
these injections; and that they were not extravasations is shown by the entire absence of points of rupture, and by the identical character of the injection masses in nodes injected indirectly from an adjacent one, under conditions of free outflow to the vena cava through the vein common to several nodes. For under such conditions serious structural derangement is avoided, or at least made improbable, because excessive pressures cannot be produced if the entrance of the injection mass is a very gradual and gentle one. The irregularity in form of the injection mass is further accounted for by the fact that the venous lacunae or true sinuses are encroached upon to a varying extent by the surrounding parenchyma, thus offering different amounts of obstruction to the onward flow of the injection masses or fluids; and by the fact that a partial injection of such wide, irregular channels must of necessity vary greatly in calibre.

The partial character of the injections in hemal nodes injected from the arterial side can be accounted for by the fact that the path of least resistance is undoubtedly in the direction of intra-vitam flow. Hence the injection mass can easily enter some empty venous lacuna or sinus, and pass directly into the vein or the larger venous radicles; rather than flow from one lacuna to another, until all or almost all are filled. Consequently it happens that only a sufficient number of venous lacunae may be injected to conduct the injection mass away as fast as it enters through the artery. Since both the arterioles and capillaries, and to a less extent also the venous lacunae, are usually in a state of partial or total collapse and more or less encroached upon by the parenchyma, they naturally offer varying resistances to the injection mass. Consequently limitation of it to certain lacunae is further promoted. The injection of the venous lacunae which lie at the periphery of the node in the lymphatic tissue, directly internal to the peripheral or subcapsular blood space, to the exclusion of those more centrally located, can be explained by the fact that the vein is often in more direct connection with them, as shown in fig. 8; and that as it leaves the node it rarely receives a number of tributaries which encircle the node, pierce the capsule, enter the lymphatic tissue, and open directly into these lacunae near the periphery. The presence of accessory or accessory tributary veins also can explain why only a very small portion of a section of a node may contain injection mass, and why the injected fluid, in case of puncture injections, can rarely be seen to leave the punctured node in several directions.

In those instances of venous injections in which some of the central or internal and the peripheral blood spaces contain injection mass, the path taken by the latter can usually be found easily in numerous places. 
These paths apparently always lie through a narrow barrier of lymphatic tissue between venous lacunae and the blood spaces. It follows from this, and from other considerations, that the peripheral and central blood spaces or islands are not necessarily, or even usually, in direct open communication with the venous system in many nodes. Hence it is easy to understand why color changes are not more manifest in hemal noles during the progress of injections from the vena cava or aorta or during bleeding, and why pressure exerted upon isolated excised nodes does not empty the filled blood spaces. Moreover, it also helps to explain why, in case of puncture injections, the injected fluid is usually seen in the vena cava before any recognizable change in appearance of the node takes place, if the injection is made slowly enough. The probable correctness of this explanation is further confirmed by the results obtained by injection in series of a number of nodes lying in a row in excised tissue, by puncture from the largest of them. When, for example, nodes I, 2, 3 and 4, having a common effluent, were injected with India ink from node I under a free outflow, a sequence of events was observed as follows. The vein draining the adjoining nodes and tributary to the vein draining node $I$, also became filled. Now if these nodes and their veins form a series of decreasing size, the resistances offered to the inflow of ink necessarily vary; and hence it may happen, as was actually the case, that node 2 becomes injected before, and more completely than nodes 3 and 4 . Consequently, node 2 showed external color changes, while 3 and 4 did not do so, or did so but slightly. On cutting such an injected series, it was found that in node 2 , which had turned black, the ink had penetrated into the peripheral and some of the central blood spaces, as shown in fig. 6 . In node 3 , on the contrary, which had undergone no color change, the ink was confined entirely to the venous lacunae or true venous sinuses; while practically no ink at all had entered node 4 , which had likewise undergone no color changes. It is evident, however, that an outward change in color would occur in all nodes, whether they contained a peripheral blood space or not, if a sufficient quantity of the injection mass penetrated the node.

It follows, from these facts, that it is generally very easy to distinguish between an arterial and a venous injection from sections of injected nodes; and I fail to see why Drummond declared it to be impossible to do so. This would be true even in the case of a venous injection, in which the lacunae, the blood spaces, and the veins were entirely empty before injection; for in such a case the arteries would remain uninjected, which would not be the case if the injection had been made from 
the arterial side. It is usually just as easy to distinguish an injected hemal from a lymphatic node injected from the vascular system; unless, perhaps, some difficulty might be experienced in case of a lymph node in which extravasation of the injection mass into the parenchyma or lymphatics had occurred. For, aside from the fact that small lymph nodes readily manifest color changes, the injection mass as a rule entirely fills the arteries or veins, is not at all or but slightly mixed with blood, is confined in vessels of regular calibre with closed walls, and consequently has not those irregular outlines characteristic of injections in hemal nodes. Moreover, vascular injections of the lymphatic nodes always show a very characteristic arborization, (fig. 9), the distribution of the injection mass throughout the specimen is quite uniform, and the capsule is rarely also surrounded by a network of fine injected capillaries, a veritable retia mirabilia. It should be mentioned in this connection, however, that Weidenreich [37] stated that the vein, and especially the artery, frequently branches as it approaches the hilus of hemolymph nodes, sending branches to the capsule and thus giving the whole a very artistic appearance, which may cause confusion in embryonic nodes.

These differences in the behavior of hemal and lymphatic nodes upon injection can easily be accounted for, it seems to me: for in the lymph nodes the injection mass merely has to penetrate permanent channels of gradually changing calibre, lined throughout by endothelium and surrounded by tissue, which can easily yield, because the lymph sinuses, which form a comparatively large portion of the total volume of the node, are easily compressible. In hemal nodes, on the contrary, the injection mass, instead of traversing a closed permanent system, must apparently traverse very irregular, often collapsed, and no doubt to a certain extent discontinuous because evanescent, channels of greatly varying calibre, which often have but minute inter-communications, and which also communicate indirectly with the blood spaces of the node. It is obvious, to be sure, that improvements in technique may invalidate some of these statements, but they are in harmony with results obtained with all solutions, suspensions and masses used in the present series of experiments.

Although the artery and vein generally enter the node together, in external form the hemal nodes of the sheep are usually oval or spheroidal, and, as previously stated, without a definite hilus. It is true that the larger nodes generally have a more definite hilus, but accessory veins usually do not have accessory hiluses. After piercing the capsule, the artery and vein generally part company at once, and only exceptionally traverse the substance of the node as contiguous structures. (Fig. Io.) 
The artery branches frequently, as it penetrates deeper into the node, the smallest branches usually being found easiest near the periphery. Although the arteries can only rarely be seen opening directly into venous lacunae, they can frequently be seen in the lymphatic tissue near them. Since the smallest arteries, arterioles, and the capillaries are practically always empty and collapsed, identification of the capillaries is necessarily difficult. Rarely an artery can be seen to traverse a small node, branching as it does so, and leaving the node approximately opposite to the point at which it entered, with apparently the same calibre. (Fig. II.) It is evident that such variations of the vascular system of the node as these can also easily account for a number of anomalous results obtained in the course of injections.

Immediately after piercing the capsule the veins, on the other hand, often communicate by means of very wide openings directly with the extensive venous lacunae which lie parallel to the peripheral (sinus) blood space, when present, near the outer border of the lymphatic tissue; but they can only rarely be seen to communicate with the subcapsular or central or internal blood spaces of the parenchyma. (Figs. 8 and Io.) Less frequently they can also be seen to communicate directly with the deeper-seated lacunae, and with large blood spaces in depleted nodes. Accessory veins, which were clearly tributary to the peripheral (sinus) or subcapsular blood space, and hence affluent veins, were occasionally found, however. (Fig. I2.) In some nodes, on the contrary, it was impossible to detect the presence of a single vein or venule within the node itself, although serial sections were made. This was found to be the case even when numerous sections of arteries and arterioles could be found. This fact, and the entire absence of injected veins within some nodes, can be accounted for by the fact that in some cases the veins apparently come into relation with the peripheral venous lacunae only. Consequently, in the absence of the peripheral (sinus) blood space they can be seen only where they pierce the capsule. Moreover, in some cases the trunk of the vein does not pierce the capsule at all, but merely comes into contact with it in such a way that communication with the intranodal circulation is effected by means of an opening in the adjacent wall of the vein, the node appearing to be sessile upon the vessel. Since no separate vascular trunk exists between the node and the tangent vein in these instances, the near wall of the latter might be thought of as being continued through the capsule, and forming its venous circulation. As in case of the artery, however, so the vein in rare instances may run nearly through the center of the node, communicating directly with the 
venous lacunae as it penetrates deeper and deeper into the lymphatic tissue, apparently without the intervention of venules or capillaries.

The above considerations and observations seem to indicate quite clearly that the blood which enters a hemal node, wholly devoid of blood islands and a peripheral (sinus) or subcapsular blood space, through the artery, passes through arterioles and capillaries directly into the venous lacunae or true sinuses. From here it may, in some cases at least, at once enter the larger central venous spaces, if present, and hence pass directly to the vein; or it may in the absence of a main intra-nodal vein enter the efferent vein directly from the lacunae. Since in the above case the absence of blood islands and blood spaces has been assumed, the relation of these structures to the circulatory conditions will be considered farther on. Consequently the only thing open to question in the above premises is the manner of termination of the arteries, their relation to the blood spaces or areas when present, and to venous lacunae, and the relation of the latter to the vein. That the arteries end in capillaries, is easy to demonstrate; but it is very difficult to demonstrate satisfactorily that these capillaries communicate directly with the venous lacunae, except experimentally. The presence in arterial injections of the injection mass in the lacunae is, of course, alone sufficient evidence to establish a direct connection between the latter and arteries; but it must be admitted that the actual demonstration of a direct continuation of an injected capillary into an injected lacuna is only very occasionally possible. This fact may, to be sure, be accounted for by the contractility of the small arterial endings, and especially by shrinkage of the node, as a result of which the injection material contained in the fine arteries is forced out into the relatively very much larger venous lacunae. The direct communication of the lacunae with the larger venous spaces, or with the veins, can, however, be seen easily, and can be demonstrated satisfactorily in both injected and non-injected specimens, even in the case of some very depleted nodes. Since the lacunae form a venous plexus of widely varying calibre, which must usually be many times the volume of the arterial tree, a decided disproportion between the size and volume of a capillary and the lacunae into which it empties naturally exists. Consequently it is evident that a decided slowing of the blood current must also take place here.

Although all attempts to demonstrate the existence of an endothelial lining in the lacunae by means of silver stains have so far been futile, it cannot be doubted from microscopical examination of the ordinary specimens alone that such an endothelium exists. For, except at points 
here and there where small gaps are found, the injection mass of India ink is always retained by a very definite wall. The existence of discontinuities in the walls of the lacunae can, however, also be demonstrated microscopically, and is further proven by the escape of some of the injected pigment or gelatine mass into the surrounding lymphatic tissue in specimens in which extravasations can be excluded because they were injected under conditions of a free outflow. This is true no matter how carefully the injection has been made. In many places a communication of the lacunae with the surrounding parenchyma is further suggested by the arrangement of the lymphocytes and erythrocytes in portions of empty or partially empty lacunae. In some instances a number of lymphocytes and blood corpuscles are so arranged as to suggest that they are entering the lacunae from the parenchyma. The peculiar disposition of these cells may be a purely accidental one, to be sure; but the comparative frequency of these very suggestive cellular arrangements would seem to imply that this is not the case. If these appearances were due to damage done to the specimens, it would be impossible to explain why the walls of the lacunae always curve gently outward and disappear among the surrounding lymphocytes, rather than ending abruptly and projecting into the interior of the lacunae and giving the appearance of torn ends. Moreover, there is nothing in the distribution of the pigment that suggests an explosive rupture, such as is frequently seen in case of extravasations.

It is to be remembered in this connection, to be sure, that since considerable quantities of erythrocytes are frequently found in the parenchyma and sinuses of lymph nodes, these must have penetrated not only the walls of the blood vessel but those of the lymph sinuses as well, in so far as they did not enter the latter through the afferent lymphatics. However, there is a marked difference in appearance of the parenchyma of hemorrhagic lymph nodes and typical hemal nodes; and no matter how the presence of erythrocytes in lymph nodes may be explained, it seems highly improbable to me that their presence in hemal nodes can be similarly explained. Helly concluded that hemorrhages are responsible for red lymph nodes, while $\mathrm{v}$ Schumacher reiterated with increasing emphasis that in both hemorrhagic lymph nodes and hemal nodes the erythrocytes likely enter the sinuses and the parenchyma through places in the walls of veins and capillaries which have been weakened by the passage of lymphocytes. Neuman thought the walls were weakened by disease. $\mathbf{v}$ Schumacher also explained the presence of extravasations of injection mass in the parenchyma of lymph and hemal nodes in this 
way, and concluded that the vascular system of hemal nodes, $i$. $e$., of nodes having no lymphatics and containing much blood, is a closed system, as is the case in lymph nodes. v Schumacher based this conclusion on the fact that the injection mass by no means always enters the parenchyma of hemal nodes, and that it occasionally does so in lymph nodes. Hence he rules out all the instances where injection mass is found outside of the circulation, but only denies the existence of a regular communication between the blood vessels and blood spaces.

Attention was called to the fact that there is a decided difference in the frequency and nature of these extravasations in hemal nodes, and that microscopical evidence of the communication between the venous sinuses or radicles and the parenchyma is not wanting. Hence, in short, the circulation of hemal nodes is similar to that of the spleen, and not to that of lymph nodes. I cannot believe that the openings in the venous sinuses are purely accidental, or that all the erythrocytes entered the parenchyma of hemal nodes at places which lymphocytes had previously weakened. Moreover, I fully agree with Weidenreich in regarding the spleen as only a higher (?) type of hemal gland. Schmalz, too, thought hemal glands may be designated accessory spleens.

Since it has been entirely impossible to demonstrate a direct communication between the arteries and the blood islands or spaces, it appears to me that these communications between the lacunae and the parenchyma must be regarded as affording the only means of entrance of the leucocytes of the node into the circulation; except, of course, by passage through the wall, as in lymph nodes, and through a free communication between the peripheral blood spaces and the veins, which occasionally exists in depleted nodes. That this statement necessarily needs modification to suit the conditions existing in seriously depleted nodes, is evident, of course. Furthermore, the fact that the blood spaces-blood islands including the peripheral blood space-always contain reticulum and have no bounding wall, while the venous lacunae and venous spaces never contain reticulum but always have a definite wall, also seems to imply that the latter represent definite permanent channels whose endothelium cannot well be co-extensive with the reticulum, and which are in direct relation with the veins. Hence the conclusion that all the lymphatic tissue and the included blood islands and blood spaces lie wholly outside the continuous circulatory system as a rule, seems entirely justified. But, whatever the relation of these structures to the circulation of hemal nodes, being inconstant and transient, they manifestly cannot be regarded as forming an integral part of a system of con- 
tinuous endothelium-lined channels. The so-called venous sinuses, $i . e$, the subcapsular or peripheral blood space as well as the central or internal blood spaces, are, on the contrary, not bounded by a definite wall, and their contents are directly continuous with the parenchyma of the rest of the node. v Schumacher too called attention to this fact, and believes that the wall of the sub-capsular blood space, which he regards as having been a true marginal lymph sinus developmentally, was probably incomplete from the beginning. Consequently then, these fluctuating vascular areas could be regarded as spaces resulting wholly or in part from a depletion of the parenchyma of the node, with subsequent or, perhaps better, simultaneous substitution of blood cells. Hence these areas can continue to exist only as long as the withdrawal of lymphocytes from the node into the circulating blood exceeds their proliferation within the node. Moreover, if the existence of a definite endothelium continuous with that of the lacunae would have to be assumed for the central and peripheral blood spaces, then it would be difficult indeed to explain why the blood corpuscles are frequently distributed quite uniformly among the lymphocytes throughout the whole node, and how such endothelial walls could so rapidly accommodate themselves to the comparatively rapid and very extensive fluctuations in size which they would be compelled to undergo in response to increase or decrease of the hemal areas. Furthermore, it would be still more difficult to explain why the injection masses become distributed irregularly in all directions among the cells of the parenchyma as soon as they pass out of the lacunae, and why the vein draining a node can never be shown to open directly into the subcapular blood space at the periphery, and can only rarely be shown to communicate indirectly with it through the intervention of blood spaces or blood islands in the interior. Such a supposition would require that the peripheral and central blood spaces must be thought of as extensive dilations which are practically coextensive in many cases with the node itself, and which communicate with the lacunae by very narrow channels. It would then also be necessary for all the lymphocytes to pass through this wall of endothelium before they could enter the circulation; and, on the other hand, the blood corpuscles would likewise have to penetrate the same wall upon entrance to and exit from the parenchyma of the node; and the only alternative to this assumption is that both arteries and veins end freely in the parenchyma-for which I can find no evidence. I fully realize that the circulatory conditions as assumed above supply no reason for the migration of lymphocytes into the blood, and that they do not account for the occurrence of gaps in the walls of the lacunae. Yet the conclusions reached are no more invali- 
dated by these considerations than the current and more or less accepted statement regarding the circulatory conditions in the spleen is invalidated by similar considerations. To be sure, a purely mechanical explanation is not suggested as adequate or final; but since this conception not only harmonizes with the observed facts but quite satisfactorily accounts for most of the difficulties, it seemed justified.

In the assumed case, then, in which practically all of the node is formed by a mass of lymphatic tissue containing a few blood cells, the supposition would be that there is a very slow movement of lymphocytes from the parenchyma into the blood stream, and a correspondingly slow, though not necessarily a purely passive movement of the blood cells in the opposite direction. Wherever local depletion of the parenchyma occurred blood islands and blood spaces would naturally form; and whenever a more or less general or local depletion of lymphatic tissue took place along the periphery of the node, a continuous or discontinuous peripheral blood space could also result. It is, of course, also probable that the accessory affluent veins sometimes present, may be in part responsible for the formation and persistence of a more or less continuous peripheral blood space, and that rapid depletion of the lymphatic tissue of the node might result in decreasing the size of the node. However, since it is unlikely that the capsule and framework of the node can accommodate themselves rapidly to the altered conditions, an opportunity would be afforded for blood to occupy the depleted periphery and so form a peripheral blood space. Since the lymphocytes must be carried away by the blood stream, they would of course have a tendency to gather about the venous ostia of the lacunae, thus explaining the occurrence of remnants of the lymphatic tissue about empty lacunae and near the periphery in depleted nodes, although it is unlikely that a purely mechanical explanation is adequate. In depleted nodes the more or less stagnant blood may then undergo degenerative changes; and, since the fragments of the erythrocytes can probably pass out easier with the lymphocytes than the intact cells, the presence of granular deposits in the lacunae would also be accounted for. If, in addition, it be recalled that some of the openings into the lacunae are undoubtedly obstructed partly or wholly by collapse of their walls through encroachment of the lymphatic tissue, the correctness of the above supposition regarding the post-embryonic genesis of such inconstant and transient structures as the blood spaces and blood islands is made still more probable.

It is interesting to recall in this connection that Weidenreich [37] considered the blood as passing through the parenchyma between the blood spaces and lacunae under ordinary conditions, but assumed that 
under extraordinary circumstances it traversed a system of arterioles which form a direct passage between the blood spaces and the lacunae, and which he regarded as playing the role of a self-regulatory system. According to this conception, for example, if for some reason the pressure within the node becomes too high, this system of arterioles is supposed to be thrown open automatically until conditions of normal, or at least of a reduced pressure, again obtain. Even granting the existence of such a self-regulatory system, I have been unable to confirm either the occurrence of arterioles uniting blood spaces and venous lacunae, or the occurrence of the thickenings in the walls of capillaries by means of which this regulatory function is supposed to be effected. Moreover, it is more than likely that if such connecting arterioles existed in any number one might reasonably expect the blood spaces and these arterioles, rather than the lymphatic tissue between lacunae and blood spaces, to become injecter. This is, however, not the case.

If the calibre of an artery supplying a node is compared with the area of the intra-nodal venous system, it is evident that the intra-venous circulation must of necessity be a very sluggish one, although increases in pressure might nevertheless slightly accelerate the intra-nodal current. This would of course be true, even if not nearly to the same extent, whether the circulation is a closed or an open one. This supposed sluggishness of the current is confirmed by the results of injections from the aorta, for it will be recalled that small lymph nodes manifested color changes almost instantly, and that the finest capillaries were later found to contain injection mass, while many of the hemal nodes remained uninjected, and only a few manifested slight color changes. Consequently it seems to me that if arterioles connected the blood spaces and venous lacunae, one might reasonably expect them to become injected, even if not as readily as the capillaries in lymph nodes. Besides, if the arterial capillaries opened directly into the parenchyma, or if other than indirect communications between the blood spaces and lacunae existed, it would be difficult indeed to explain why blood should accumulate within the node, as it usually does. It is also evident that if the disposition of the vascular circulation in hemal nodes were comparable to the lymphatic circulation in lymph nodes, it should not be so exceedingly difficult to inject hemal nodes from the aorta; for the ease with which lymph nodes can be injected from the periphery, and the speed with which they manif est color changes are, of course, striking. Hence it seems to me that these considerations alone suffice to establish the fact that the relation of the peripheral and central blood spaces to the veins of hemal nodes must be essentially different from that of the lymphatic vessel to the peripheral and central sinuses of lymph nodes. 


\section{The Microscopic Structure}

Under low-power magnification a hemal node in section may show nothing but a thin capsule containing a solid mass of lymphoid tissue with few or no follicles or trabeculae, and with but a sprinkling of barely noticeable erythrocytes. Or, on the other hand, it may look like a sac filled with blood in which the coarser framework of the node is revealed here and there, but with only a few small masses of lymphoid tissue with or without lacunae containing some blood cells and granular detritus. In short, then, the appearance of a hemal node on section may be similar to that of a section of sheep's spleen without Malphighian corpuscles and few erythrocytes and but few and small trabeculae, on the one hand; or that of a sack of blood containing a few small islands, or merely scattered lymphocytes or groups of them lying near small connective tissue trabeculae, on the other. Rarely, too, one finds a practically empty node containing but little lymphatic tissue surrounded by scattered erythrocytes and enclosing wide-open spaces; the venous lacunae of Weidenreich, containing some granular detritus and degenerated blood corpuscles. Between these extremes literally every conceivable gradation is found. The cross-section, for example, may be crowded with follicles (figs. 6 and 14 ) which encroach on each other, on the blood islands, and even on the peripheral (sinus) blood space; or, perchance, they may be absent altogether (fig. I5). A classification of follicles into definite types, as reported by Vincent and Harrison [28], was never possible; and such differences as were observed were structurally of a very minor character. A like inconstancy is found in case of the empty venous lacunae found in the parenchyma, which are frequently very conspicuous in nodes containing much blood but little lymphatic tissue. (See figs. I6 and 17.) It is these spaces, I take it, which have probably been mistaken for lymph spaces.

Equally great variations exist in all the constituents of hemal nodes, save perhaps the capsule and the artery. These are the least subject to variations; although it is evident that in a node which practically represents a sac of blood the original distribution and disposition of the artery must also have been modified very profoundly. It follows, to be sure, from these considerations that a node having neither blood islands nor blood spaces, not even a peripheral (sinus) blood space or evident venous lacunae, may yet be a true hemal node. And, on the contrary, it also follows that a node containing a mere remnant of lymphatic tissue in a mass of blood may also be a true hemal node (figs. I 8 and 19). This being the case, it is highly probable that these facts account in some measure at least for the confusion regarding the occurrence of mixed nodes, . 
and possibly also for the contention that a transformation occurs from hemal to lymph nodes, and vice versa. For, as already stated, such a transformation might well be assumed to occur, because an actual series of nodes with but slight structural differences-except circulatory-between the successive nodes, can be formed with true hemal and lymph nodes, as extremes. In such a series it would be entirely impossible to differentiate many of the intermediate nodes from external appearances, or by a cursory microscopic examination; and it should be remembered that injection methods alone made positive identification possible in many cases of these apparently transitional forms.

In those nodes in which the blood corpuscles were not intermingled more or less uniformly with the parenchyma, they formed masses which contained some lymphocytes, especially at the periphery of the masses. These local accumulations of blood-cells-blood islands-vary in size from small groups of cells to larger masses which may compose the greater part of the area of the node. There are nodes, for example, containing a single blood island practically co-extensive with the node, and forming perhaps nine-tenths or more of the area of the section (figs. 15, I8 and 19). Others, on the contrary, may contain hundreds of minute blood islands which may nevertheless form but an insignificant fraction of the total volume of the node. When small, numerous and isolated these islands often give a spotted appearance to the cross-section under low-power magnification. If, on the contrary, they are very large, they are often ill-defined, generally irregular in shape, and more or less continuous with each other, with the blood in the peripheral blood space, and with the large central-internal-spaces, if present. A union of the peripheral and more external blood spaces into central collecting spaces was never observed.

It is evident, of course, that a peripheral blood space can exist only when sufficient lymphatic tissue is preserved; for when the latter is greatly reduced in quantity, all boundaries are completely effaced, thus allowing the blood islands or spaces to merge. Hence as more and more of the lymphatic tissue of the node disappears and the total hemal area becomes larger and larger, a stage is finally reached in which the peripheral and central blood islands or spaces merge into an area in which only remnants of the once predominant lymphatic tissue are found. But whether these blood islands in the parenchyma were large or small, the blood was only very rarely found to be in a state of evident degeneration, except in nodes which were largely or almost wholly devoid of lymphatic tissue.

The cellular content of the blood islands did not vary markedly from that of the veins; although at the periphery of the islands, and especially 
at the inner margin of the peripheral blood space, there were fewer polymorphonuclear leucocytes and eosinophiles, but more lymphocytes. However, in some of the largest blood islands, and in nodes in which blood had so extensively displaced the lymphatic tissue, extremely few lymphocytes were found among the solidly packed erythrocytes.

Eosinophiles were present in the hemal areas in small numbers only, being confined almost entirely to the surrounding lymphatic tissue. In the case of very large blood islands the intermingling of erythrocytes and lymphatic tissue was occasionally so extensive, however, that there were approximately as many cells of the one kind as of the other. However, in some cases most of the blood was found distributed rather evenly among the lymphoid tissue. It seems probable that this condition results from a secondary invasion of the blood spaces by the surrounding lympliocytes, rather than by an invasion of the surrounding parenchyma by erythrocytes, although, to be sure, primarily the lymphatic tissue was displaced by blood cells. No matter what the character of a node, the boundaries between the blood islands and lymphoid tissues were illdefined, as a rule (see fig. 20). Occasionally, however, a well-defined wall, of rather coarse reticulum, was present between the two (fig. 2I). This bounding reticulum between blood islands and lymphatic tissue was seldom very apparent, except in a few nodes which contained so little blood and lymphatic tissue that they were practically empty. In these nodes the lymphatic tissue had been reduced to such an extent that one might rightly speak of islands of lymphatic tissue in a hemal area. As might be expected, however, there seemed to be very little intermingling of the blood and lymphocytes in by far the greater portion of some of these nodes. Moreover, since these walls of reticulum are often similar or identical to the walls of the apparently condensed reticulum seen at the periphery of a follicle, it is possible that the accumulation of blood in the empty reticulum may be an important factor in producing them. This supposition seems to be supported by the fact that they were seldom or only partially present, around very small blood islands. Moreover, whenever the total amount of blood was larger the contiguous surfaces of blood and lymphatic tissue were often indicated by a gently curving line, instead of by a very irregular and ill-defined one. However, here and there a portion of lymphatic tissue of irregular form might nevertheless extend boldly out into the surrounding blood. It is only occasionally that blood islands are found within the follicles; and when so found they are generally small, and never seem to be continuous with those outside of them. Nevertheless their absence rather than their presence here would seem to need an explanation. 
In addition to the large venous spaces in direct communication with the vein, usually located near the center of the node, when present, there are small and more numerous ones, termed venous lacunae by Weidenreich [37]. These dilated empty, or nearly empty, spaces are apparently most numerous and conspicuous in nodes which contain much more blood than lymphatic tissue (figs. I7 and 19). Indeed in such nodes they are frequently so numerous, so large, and so devoid of celluar content that they may give an almost fenestrated appearance to a section. In these specimens-and in general, for that matter-they are most evident near the periphery (figs. 8 and II). In depleted nodes this fact can, to be sure, be easily accounted for by the fact that most of the remnants of the lymphatic tissue are for some reason found in this location (fig. 18); but why they should be more evident here than elsewhere in the more typical nodes (fig. 8) is not so obvious. Although the configuration of these lacunae or true venous sinuses is an extremely irregular one, and although their boundaries are not always well defined, it was nevertheless quite often possib!e to pass from one lacuna to another, along almost the whole circumference of a section of uninjected nodes. If, however, they were small, their communication, and in fact their continuity with other lacunae, was not so evident, although such communications and continuity undoubtedly existed. This apparent absence of inter-communications between lacunae can probably be explained by the fact that when the walls of the lacunae are in contact it is very difficult indeed, or impossible even, to distinguish the latter from apposed reticulum fibers. Nor does the fact that no lacunae whatever were visible in sections of some nodes which had the appearance of splenic tissue, for example, necessarily imply that none existed; for a hemal node-other than a completely depleted one-without lacunae would seem to be an impossibility, because of the probable or even necessary circulatory conditions which their absence would seem to imply. The absence of lacunae would practically transform the vascular system. Moreover, if the results of the many injections of the venous system of nodes can be used as a criterion, it is certain that lacunae are distributed throughout the entire node, with the possible exception of the follicles; unless, as seems improbable to me, the occasional presence of India ink in the latter can be taken as satisfactory proof of their existence here. Since, of course, the lacunae contain no reticulum, they must, I believe, be regarded as practically permanent structures which are an integral part of the venous system and intermediate in position in the circulation. Many of them persist until the last remnants of lymphatic tissue disappear (fig. 18). Moreover, whatever their relation to the arteries, since 
they are usually empty save for small amounts of granular material (fig. 2I), it is clear from this and other direct evidences that they communicate rather freely with the large central venous spaces and the draining veins. That they must, however, also communicate in some manner with the lymphatic tissue and the blood islands and blood spaces, is indicated by such appearances as those represented in fig. 20 , and by the results of many puncture injections, as well as by other considerations.

While, then, it was comparatively easy to determine the direct connection between lacunae and veins, microscopically alone, their relationship to arteries could be demonstrated satisfactorily only by injection methods, for no matter how close to a lacuna the arterial terminations were, they were only seldom seen to open directly into them (fig. 23). Nor was it easily possible to demonstrate a direct communication between venous lacunae and the blood islands or blood spaces (fig. 24), or between them and the peripheral or subcapsular blood space, except in nodes whose structural relations had been profoundly altered as a result of decided depletion of the lymphatic tissue. But even in most of these specimens a narrow and more or less perfect barrier of lymphatic tissue almost invariably separated them from the blood islands or blood spaces (figs. I3, 21 and 22). The existence of these barriers of lymphatic tissue between the venous lacunae and the peripheral blood space on the one hand, and the central or internal blood spaces or blood islands on the other, as well as the almost constant presence of an amorphous or slightly granular deposit in many of them, even in the case of nodes practically devoid of lymphatic tissue, are particularly significant, it seems to me, for the elucidation of the somewhat obscure circulatory conditions. Besides, that the interpretation of these venous spaces or radicles as lymphatic spaces, however excusable, is erroneous, must be evident from the above experiments and observations.

In some depleted nodes, and very rarely also in others, large connective tissue septa divide the node so completely that the individual subdivisions might almost be considered as separate nodes (fig. I6); but no specimens were found in which the lymphatic tissue could be said to be fibrous or muscular, as stated by Vincent and Harrison [28]. Indeed, in the great majority of cases, there are no evident septa or trabeculae extending inward from the capsule and subdividing the node. The coarser reticulum, however, is generally plainly visible in the peripheral blood space, in many blood islands (fig. 25), and throughout depleted nodes, by means of low magnification. That this reticulum is more conspicuous in the peripheral blood space is, of course, due to the fact that 
it is coarser here where it comes into relation with the capsule, and because it is generally obscured much less here by the presence of celluiar elements. In the deeper portions of the node it is much finer, denser, much less cellular, and sometimes not at all apparent in the follicles in sections stained in the ordinary way. The size of the meshes of the reticulum also vary markedly in different portions of the node. They are largest where the fibers are coarsest, and smallest where they are of greatest tenuity. Although some very fine fibres can be found in practically all portions of the parenchyma, it is in the follicles where the finest reticulum is found. Here the meshes are often so small in section that they contain but a single cell. As in the follicles of lymph nodes, the reticulum is less evident in the center, where only an imperfect network can be demonstrated. Were this difference less constant it might possibly be due to variations in staining power of the reticulum, or to a faulty technique, but the same results were obtained by the special stains used. Near the periphery of the follicle, on the contrary, the fibers seem crowded together, and consequently are generally very evident, because they are coarser and have a rather circumferential arrangement. The finest reticulum fibers noticed were so minute that they appeared as extremely fine lines under the highest magnification used ( $x$ I 340 ).

In the center of many good-sized blood islands, or in blood spaces, reticulum could never be demonstrated by the Bielschowsky or any other method. Moreover, in empty or in partially empty nodes many of the coarser reticulum fibers in the empty blood spaces seemed to end abruptly, as though they had been forced asunder. Nor was it difficult to find cells with six or more processes, some of which terminated in free ends a short distance from the cell. At the border of large blood islands, or of blood spaces, a very definite bounding or confining layer of coarse reticulum, from which branches extended into the blood islands, was frequently present. In some cases these walls of reticulum were formed by several parallel fibers, which looked as though they had been crowded together more or less, and which very closely simulated conditions found at the periphery of the follicles. Were it not for the fact that this wall of reticulum which separates the blood islands from the lymphatic tissue gives off branches which are directly continuous with the adjacent reticulum on both sides, it would be very difficult indeed, or impossible even, to distinguish the walls of some empty blood spaces from those of empty venous lacunae. However, generally only a portion of the circumference of a blood island was thus bounded, the remainder of the boundary being formed by the parenchyma of the node, in the bounding area of which a gradual 
change from pure lymphatic tissue to the blood contained in the blood spaces could be seen. These transitional areas strikingly demonstrated the relations existing between blood islands or spaces and the parenchyma of the node, and in them it was easy to see that the blood in the blood islands had probably merely replaced the lymphocytes.

Aside from small quantities of plain muscle found near blood vessels, none was observed save in the capsule, where a few fibers could occasionally be distinguished, but these too were probably associated with blood vessels. Hence the conclusion that involuntary muscle is a purely incidental constituent of the hemal nodes of the sheep, seems justified; and the statement that hemal nodes can alternately contract and relax, seems a highly fanciful conception, except in so far as such alternations in volume may be the result of a varying pressure or fluctuations in calibre of the arteries. I am fully aware that these observations are somewhat at variance with those of Robertson [24], Weidenreich [37] and v Schumacher [27]. According to Weidenreich unstriated muscle and a few elastic fibers are found, especially in the inner layers of the capsule. Both Weidenreich and $\mathrm{v}$ Schumacher state, however, that these constituents vary greatly in amount; and the former adds that smooth muscle was not found in the lymphatic tissue.

Although sections taken from a number of nodes were stained with different elastic tissue stains, undoubted elastic tissue fibers were never found. However, since all stains used for this purpose also stain the reticulum to some extent, it is practically impossible to differentiate these two kinds of fibres definitely by the ordinary elastic tissue stains. Moreover, the fine reticulum fibers which are very numerous often branch and have a wavy outline so as to simulate elastic tissue fibers very closely. Hence the evidence obtained in this investigation is an entirely negative one as far as the occurrence of elastic tissue is concerned.

Neither could fat cells be demonstrated in the parenchyma of a number of nodes examined after the use of special methods of fixation and hardening, such as those of Vom Rath, Flemming, Herxheimer, Hermann, or by the use of osmic acid. Negative results were also obtained with Herxheimer's stain as modified by Bell. The only nodes in which there seemed to be a rather ill-defined line of demarcation between the parenchyma and the surrounding fat were developing nodes, or specimens in which the generally inconspicuous capsule was extremely thin in some places. These observations regarding the relation of the fat, made on several hundred nodes taken at random from a large series of carcasses of sheep, bovines and goats, stand in striking contrast to those of Meek [17] 
on nodes from three pigs. Meek says that "On microscopical examinations they (the glands) are seen to possess a very thin capsule and in some cases a distinct capsule cannot be said to exist, the peripheral sinus of the gland being directly contiguous with the periglandular fat, and the cellular tissue of the sinus spreading between the contiguous fat cells. This condition much resembles that seen in the marrow of the long bones at the junction of cellular and fatty marrow." These observations of Meek are similar to those made on sheep by Clarkson [2], who stated that the cells of the surrounding fat are often in contact with the adenoid tissue. It is particularly interesting in connection with Meek's observations that $\mathrm{v}$ Schumacher failed to find hemolymph (hemal) nodes in the pig. Both he and Baum and Hille, who according to v Schumacher first directed attention to the matter, and also Baum, found fat cells bordering the marginal sinus in most of the lymph nodes of the pig. Baum regarded this as fat formation on part of the reticulum, beginning from the periphery and leading to complete atrophy of the node, as due to age; but $v$ Schumacher found that fat is already present at six months. The latter also called attention to the well-known fact that similar changes occur in other animals, and that erythrocytes are normally present in the lymph sinuses of lymph nodes of the pig.

Intra-capsular sinuses, or blood spaces, as described by Robertson [24] as extending one-fifth of the distance around the gland, were not seen; although it is not rare to find free blood in the looser portions of the capsule. Neither did nodes which were almost depleted of lymphatic tissue, and which might perhaps be considered as undergoing retrogression, show the least sign of fatty degeneration. However, Warthin [33], in writing of the marrow lymph nodes of man, reported the finding of fat cells throughout this type of node, and also maintained [34 and 35] the development of hemolymph nodes from fat and their degeneration into fat; but Vincent and Harrison [28] reported that "In no instance did we find any fat cells inside the capsule" in the sheep and ox.

The conclusion that the blood islands and blood spaces, both peripheral and central, are transient, and perhaps even quite incidental structures, seems amply justified. Present now and absent then, found in this node and not in that, their usual presence in developing nodes even, does not signify, it seems to me, that they are indispensable constituents of hemal nodes. It is not uncommon, for example, to find a portion of a node containing many follicles which are in a state of proliferation, and which encroach upon both the peripheral and the central blood spaces or blood islands. That such a process must often result in the complete obli- 
teration of both peripheral and central blood spaces seems very likely indeed. Moreover, since the blood spaces are usually engorged with blood, which cannot be expelled from them by external pressure even when they are large, further proof is given that they probably are not as a rule in free direct communication with the veins. For these and other reasons, I have come to regard the blood islands-the blood spaces including, as a rule, the peripheral or subcapsular blood space-as very largely representing areas in which the parenchyma of the node has become depleted of lymphocytes, whose place has either wholly or partly been taken by blood. Since, however, this blood is usually in an apparently good state of preservation, it seems to follow that these areas when large must nevertheless have fairly good communications with the vascular system. That they are probably not in free communication with the arteries, however, seems to be suggested by the fact that no such communications could be demonstrated microscopically, and that they were not injected from the aorta; unless the supposition that the blood contained in them prevented the entrance of the injection mass, can be accepted as an adequate explanation. The adequacy of the latter explanation seems doubtful, however, since, as already stated, it is usually impossible to demonstrate arterioles or capillaries opening directly into the blood spaces, although the direct communication of the latter with veins is occasionally seen. For even in the case of the small and definitely circumscribed blood islands, which are completely surrounded by lymphatic tissue and which lie more or less distant from neighboring blood spaces, a direct communication with the arterial system could not be demonstrated. Consequently it is difficult to believe that such a direct communication, if it occurs at all, represents normal or at least common conditions.

\section{The Cellular Content}

For the purpose of studying the cellular content of hemal nodes, blood smears and cover-slip preparations from fresh nodes and from the blood of the vein draining the node were also examined. In order to be certain that the veins from which the blood was taken actually drained a hemal node, injections into the node were made later. Although no full discussion is here intended, the large number of nodes examined and the many different staining methods used, afforded every opportunity for a comprehensive study of the cellular content.

As is well known, the ordinary lymphocytes form the great bulk of the parenchyma of most nodes. Small areas in which they mingled in anything like equal proportions with erythrocytes were only rarely found, 
and specimens in which such intermingling occurred throughout an entire node, or an entire section even, were still less frequent. Although a good deal of intermingling occurred in some specimens, both lymphocytes and erythrocytes were segregated more or less distinctly as a rule; and even in nodes which contained but remnants of lymphatic tissue the lymphocytes were formed into small circumscribed areas or groups near the radicles of the venous system. The constancy in staining characters of the lymphocytes was in striking contrast to that of the erythrocytes and acidophiles. However, in nodes which practically represented a sac of blood in which the small remaining masses of lymphocytes were surrounded more or less completely by remnants of the framework of the node, both protoplasm and nuclei of the lymphocytes occasionally assumed very irregular shapes. In other cases the nuclei stained poorly, and the nuclear network was indistinct; while in still others they were pyknotic or had apparently fragmented.

Variations in the size of the lymphocytes within the same or in different nodes were considerable; but often these were apparent and not real, for these fluctuations were chiefly due to variations in the size of the nuclei, rather than to differences in the quantity of cytoplasm present. Since however, the cell outlines were very frequently indistinct, while those of the nuclei were well defined, these observations were not wholly satisfactory. The protoplasm was often not eccentric; and where, as in case of the center of the follicles, the cells were closely packed, they were much larger, had vesicular nuclei, and frequently a more or less polygonal outline. The size and number of the chromatin granules varied greatly, the smaller ones being more common near the periphery of the nucleus, while the larger ones, on the contrary, lay nearer the center. The chromatin network too was often quite distinct, but well-defined nucleoli were infrequent. Moreover, the nuclei of cells which lay near the periphery of the follicle, were usually more regular in shape, and were often entirely filled with granules; while those nearer the center, besides usually being vesicular, larger, and more irregular in shape, contained but few granules. Unmistakable mitotic figures could not always be found in the follicles, and still less frequently in other parts of the nodes. Since, however, a comparatively small number of specimens were prepared for this particular purpose, these statements may not be thoroughly representative.

The apparently excellent state of preservation of the blood, in both the parenchyma and subcapsular blood spaces, in the great majority of nodes, is in marked contrast to the degenerated condition frequently observed in the lacunae of Weidenreich or true venous sinuses. Nucleated 
red cells were found nowhere, however, save in foetal nodes. Although the erythrocytes were generally well preserved, all gradations between perfect cells and small masses of cell detritus were found in specimens prepared in many different ways. As might be expected, however, they were frequently well preserved in nodes depleted of lymphatic tissue; although the absence of fragments of erythrocytes within these nodes may have been due, in part at least, to the freer circulation which must exist in them and which assures a freer drainage of the node. In some specimens which were only partially filled with lymphocytes and blood, many erythrocytes assumed most unusual shapes, which probably cannot be attributed to poikilocytosis. In some Zenker preparations, for example, many isolated cells which were not crowded upon by others were truly cupshaped, as has been variously observed. The outlines of others were ovoid, or crescentic; while still others looked as though the cell membrane had ruptured, and retracted somewhat, thus leaving an opening with an irregularly torn margin. Among these cup-shaped cells some fragments of erythrocytes were always found; but most of them stained no differently than the normally-shaped ones. Aside from this disintegration, the erythrocytes, particularly in nodes depleted of much of the lymphatic tissue, also exhibited some variability, in staining characters. In Zenker preparations, most of them usually stained a golden yellow with orange G; but groups or areas of others took the pink of Congo red or eosin; and practically all gradations in staining reactions were found between these colors. The best-preserved cells usually stained with orange $\mathrm{G}$, as was the case in embryonic nodes; although it must be added that irregularly shaped erythroblasts contained in the latter, occasionally stained pink. Since, however, unmistakable fragments of erythrocytes also often stained pink, it may be inferred that this selective staining quality on part of some erythrocytes probably signifies little else than incipient degeneration. Since some of the fragments of erythrocytes were circular in outline, they simulated blood platelets so closely that if found in circulating blood they would in ordinary preparations probably be indistinguishable from them. Although it was sometimes difficult or impossible to stain the erythrocytes in the blood spaces satisfactorily, it is doubtful whether this fact can be attributed to a deficiency in hemaglobin, as held by Meek [ 17 ], in case of cells from pathological glands taken from the human body.

Polymorphonuclear leucocytes were common, especially in some parts of the parenchyma and in the veins. They were rather uncommon in the blood islands and in the peripheral blood space, and were not observed 
in the follicles, save when these contained blood. Large mono-nuclear leucocytes were found frequently in the lymphatic tissue, and in greater numbers in cover-slip preparations taken from the vein draining a node. In the arteries, on the other hand, and in the blood islands, they were found in smaller numbers only.

Although individual phagocytes could usually be found, marked phagocytosis was not a constant phenomenon. In some cases, however, the whole section was dotted with scattered polymorphonuclear leucocytes, which were filled with fragments of erythrocytes and fairly well preserved cells. These phagocytic leucocytes were not much enlarged, as a rule, and were always well preserved. In some cases, however, so many and such extremely large phagocytes were present that the whole section of a node was seen to be studded with them on lower power (x 42) magnification. Since these large cells were filled so completely with erythrocytes and fragments of such, they gave the section the appearance of containing numerous small blood islands or areas. The nuclei of these large endotheloid cells, a group of which was sometimes contained in a follicle, were large, oval and vesicular. Occasionally similar isolated cells were found in small numbers, in the hemal areas of nodes in which phagocytosis by polymorphonuclear leucocytes was very active; but this association was not at all constant.

Besides typical eosinophiles, which were sometimes exceedingly numerous and rarely arranged around an artery (see fig. 26), others with less evident granules were not uncommonly present. These were usually most evident in sections of nodes fixed in acetic bichloride and stained in haemotoxylin followed by rubin S. Besides these atypical eosinophiles, other generally much larger acidophile cells with vesicular and occasionally pyknotic nuclei, were also found in developing and mature nodes. They varied considerably in size, and were undoubtedly phagocytic in some cases.

The most uncommon cells found in the course of this investigation were of course the poly- and megakaryocytes, of varying sizes and shapes. Some of these multi-nucleated (?) cells were extremely large, and had a very irregular outline. In fact they were rarely so irregular that the outlying portions suggested the occurrence of pseudopods and amoeboid motion. These cells, which were usually found in the lymphatic tissue, were sometimes surrounded more or less completely by an empty space of varying width, which was, however, seldom so large as to accommodate additional cells. Although more numerous in developing nodes, there was nothing which indicated that they are character- 
istic of any particular type of node, or that they are confined to any particular stage of development. They were present in foetal nodes, in those from young lambs, and in those from adult sheep as well. Usually they lay somewhat isolated, though rarely a group of three or four was found. They varied much in size, a single section of the largest extending halfway across the field of a No. 5 ocular and homogeneous immersion (Zeis) and through a thickness of $10-50 \mu$; the largest measuring $30 \times 50 \times 30 \mu$ by filar micrometer. The protoplasm, which was non-granular, took an eosinophile stain and was not surrounded by a recognizable cell membrane. Rarely a somewhat hyaline border, suggesting degenerative changes, was noticeable. The vesicular well defined, apparently separate, nuclei, were generally circular or irregularly oval in shape, had a distinct nuclear membrane, and varied from about 5 to $20 \mu$ in size. When large and single, the nucleus was frequently lobed or crenated; and when multiple, as many as six could often be seen without a change of focus, assembled in the center or scattered about at random in the protoplasm. The chromatin granules in the nucleus were few and small, the nuclear network indistinct, and mitotic figures or conclusive evidences of amitosis were never observed. However, since only a comparatively small number of these giant cells could be observed, it would be unjust to over-emphasize these facts. Vacuoles were seen only occasionally; but some cells seemed crowded with inclusions, some of which simulated erythrocytes and platelets quite closely; while still other areas looked like local condensations in the protoplasm, which in the stains used suggested areas of degeneration, some of which looked not unlike Negri bodies. In some cases these local condensations or degenerations which stain a deeper pink are surrounded by a clear area or halo, which gives the whole structure a superficial resemblance to a nucleated cell; and in other cases such were actually included in the periphery of the protoplasm.

Plasma cells were found in small numbers in some of the specimens only. They were demonstrated most successfully by Unna's polychrome methylene blue, after fixation and hardening in alcohol. Preparations were also stained according to Ehrlich, Ehrlich and Westphal, and also by Unna's polychrome methylene blue followed by orcein; but the results obtained by these stains were not as satisfactory. There was nothing characteristic about their distribution or structure, for isolated specimens were scattered about at random, and were also found in some of the follicles. I do not regard their presence as unusual or specially significant, or indicative of inflammatory changes, for the nodes were normal specimens.

Mast and iron containing cells were never found, although special 
methods were used and repeated examinations made; and pigmented cells were seen but seldom. In the search for iron, for example, all known methods were used, without a single positive result being obtained. However, since Weidenreich [38] found lumps of pigment of a brownishyellow color which gave the reactions in sections treated for inorganic iron with ferrocyanide and hydrochloric acid and also with ammonium sulphohydrate, it is possibe that there is considerable variation with respect to the presence of iron, or that the nodes under observaion were not hemal nodes. This supposition also receives some support from the observation of Weidenreich that only a particular type of cell, designated as a "direct hemophage" by him, contained inorganic iron. I am convinced, however, that not every cell which might justly be regarded as a direct hemophage gives the ferro-cyanide-iron reaction. In fact none of these cells, in the large series of nodes examined, gave this reaction. In the search for other pigment no special methods were used, since ample opportunity for its detection was afforded by the many different methods of fixation and staining used. The great majority of hemal nodes contained no pigment; but a group of peculiar and uncommon lymph nodes, which will be discussed presently under the designation of mixed nodes, contained very much pigment. However, only about a dozen of these nodes were found, among many hundred specimens examined. Indeed, the absence of pigment is an important characteristic of typical hemal nodes, and is particularly interesting because such decided destruction of erythrocytes apparently occurs in so many of them. $v$ Schumacher too called attention to the fact that pigment is usually absent in the hemal nodes of the sheep.

\section{The Question of Mixed Nodes}

As already stated and emphasized, the exceedingly protean character of hemal nodes often makes it difficult or impossible even to distinguish them from lymph nodes by inspection, or even by microscopical examination of a few sections. Because of this difficulty, no doubt, the supposition that mixed or true hemolymph nodes exist seemed justifiable to many investigators. Helly [II], Forgeot [6 and 7], and $\mathrm{v}$ Schumacher [27], for example, stated that all transitions can be found in the sheep, from glands with lymphatics to those without them. Warthin [34] and 35] made a similar statement regarding lymph nodes in general; and Forgeot even insisted that injections are unnecessary to demonstrate the presence of lymphatics in hemolymph nodes. Forgeot nevertheless stated that hemolymph glands may be wholly without lymphatic connections, and also that the lymphatics join the developing hemolymph node 
later; while $\mathbf{v}$ Schumacher concluded that they lose them. Similarly for man Warthin [33] stated that he found combination forms of spleeno- and marrow lymph nodes, as well as all manner of transitions between spleno-lymph glands and lymph glands and the spleen. Warthin [33]-and later Lewis [I3 and 14]-further stated that there may be blood sinuses in one part of a node and lymph sinuses in the other; and Warthin [3I] added that "transitional forms cannot be distinguished from congested lymph glands." If this be true, then the question as to how it is known that true hemolymph nodes, $i$. $e$., nodes other than lymph nodes, in similar relation to both the lymphatic and the vascular systems as that of lymph nodes to the lymphatic system-i. e., having sinuses common to both systems-occur at all, seems a pertinent one. For if transitional forms cannot be distinguished, what basis is there for any, not to say an elaborate, classification? Meek, who studied the lymph and hemolymph glands of man in pathological states, declares somewhat similarly, that "In a few cases where hemolymph glands were present (Meek does not state how they were identified as such) in large numbers, I have removed and examined all the easily found lymphatic glands of the same group, and found them all to show a practically identical condition."

It is not clear, to be sure, how identification of and differentiation between lymph and hemolymph nodes in "identical condition" was possible. Nevertheless, Meek continues: "It appears, then, that every lymphatic gland is a potential haemolymph gland. The experimental production of such glands in the guinea-pig is easy of accomplishment. . . ." According to Meek, then, a hemolymph node is only a lymph node under abnormal or altered conditions. That is, any lymph node subjected to an injury or to abnormal conditions either in disease or experimentally, can quickly be converted into a hemolymph node! This would also seem to be Retterer's conclusion regarding the nodes of guinea-pigs, which conclusions are discussed elsewhere* with Meeks' results, in connection with the writer's findings and experiments on these animals and on dogs. Meek, although speaking of two kinds of nodes and of the conversion of one into the other, concluded, however, in direct contradiction to Warthin and to himself, that there is no justification for classifying human nodes as lymphatic and hemolymphatic. A similar conclusion regarding the relation between lymph nodes and hemal nodes was reached by Retterer [22], who stated, in short, that all lymphatic nodes possess the same structure and functions, and

*Journal of Experimental Zoology, 1914, and Anatomical Record, I9I4. 
whether they contain blood or not depends only upon the force of the lymph stream. It suffices to change the arterial pressure, and consequently the lymph pressure, in order to convert a gland from lymph to haemolymph gland, and vice versa. $\dagger$

In the course of this investigation only a few observations were made on human nodes; but as far as these and the examination of nodes from bovines, goats, dogs, cats, rabbits and guinea-pigs were concerned, no evidences whatever for the existence of combination forms or the conversion of one into the other, have been obtained. Because of the comparatively small size of the hemal nodes in most of the domestic animals injections were made only on the sheep, bovines and in a few goats. $\neq$

Some of the lymph nodes which are indistinguishable often from hemal nodes save by injection methods, are comparatively large specimens which have the color of certain hemal nodes at one end and of lymph nodes at the other. Although these hemorrhagic or hemal portions are often irregular in outline and occasionally ill defined in many cases, they are nevertheless quite well defined to the unaided eye. In some cases this hemorrhagic area is confined to the interior of the larger nodes, and is consequently not evident on external examination alone. In addition to such specimens, others which represent all shades in color from the gray of lymphatic nodes to a chocolate-brown or a magenta-red, are not very uncommon. Still others are so deeply pigmented that they are black, and at once suggest anthracosis. These dark pigmented nodes also may simulate rare hemal nodes in external appearance, and hence may likewise suggest the occurrence of an intermediate group of mixed nodes.

Lewis [13] also emphasized the fact that intermediate forms are very numerous, and strangely enough referred to glands in ungulates "Many of the largest of which are (9-10 cm.) long and have a certain structure recently described by Weidenreich." The latter is then said to have described an intermediate form, having blood sinuses only in one portion of the node and lymph sinuses only in the rest, each kind of sinus occupying a distinct portion of the node. Although emphasizing the fact that there are ordinary lymph glands in which ". . . very similar and easily mistaken appearances are presented," Lewis further

† See also Retterer, Edouard: Des hématies des mammifères. Jr. de l'anat. et de physiol. Tome XLIII, I907.

$\$$ Hemal nodes were not found in cats, dogs, rats, rabbits and guinea-pigs unless we regard them as identical with supernumerary spleens. 
states that there rarely are other transition forms, in which there is a mixture of blood and lymph streams in one portion and only lymph in the sinuses of the rest of the node, on the other hand; and cases in which both streams mingle in one portion, while the rest of the node contains blood sinuses only.

Vincent also believed in the existence of nodes having sinuses common to the lymphatic and vascular systems, as also Robertson had previously stated.

Some of the difficulties in identification met with in gross appearance are likewise encountered upon microscopical examination of separate sections; but if a group of mixed or transitional nodes really existed with sinuses common to the vascular and lymphatic circulations, it is clear that it should be possible to inject both the lymphatics and the veins from them. For, as is well known, puncture of a lymph node always results in the injection of the lymphatic and not the vascular circulation of the node-except accidentally, and only very rarely; while, as has been amply established, puncture of hemal nodes, on the contrary, always results in injection of the veins draining the node, and occasionally the vein draining an adjacent node, but never the lymphatics. Hence, if mixed or true hemolymph nodes existed, the injection mass should appear both in the vena cava and in the thoracic duct. Such was, however, never the case; and after a little experience it was quite possible indeed to foresee, in most cases at least, what the results of puncture injections into a given questionable node in situ on the fresh carcass would be. For example, the microscopically pigmented nodes which suggest anthracosis, were generally found in connection with the lymphatic system. The same was also true of rare and rather large nodes found in the sub-lumbar region in sheep, a portion of which was typically lymphatic in color and the rest quite as typically hemal. If these large, apparently combination forms, were true hemolymph nodes, it should, of course, have been possible to inject at least the lymphatic vessels from the typically appearing lymphatic portion, and the veins from the typical hemal portion. However, this was never possible. Such nodes in the sheep were found to be either in connection with the vascular or with the lymphatic system, but never with both, and usually with the latter; nor has anyone injected the veins from one and the lymphatics from the other portion.

Since the only reliable criterion-the injection method-for distinguishing a lymph from a hemal node, was accepted only as a result of experiments, and is not a theoretical or preconceived one, it follows, to 
be sure, that the above results demonstrate that the mere presence or absence of free blood in the form of blood islands or intermingled with the parenchyma cannot and does not convert a lymph node into a hemal node. For if this were the case then there could, of course, be no such organs as true hemal nodes. The fundamental difference between lymph and hemal nodes, as pointed out and reiterated by Weidenreich, is the presence or the absence of lymphatics. It does not consist of or lie in a mingling of the vascular and lymphatic circulations of the node, or in the possession of sinuses and blood spaces common to both; nor merely in the presence of blood in the lymph spaces of lymph nodes. Furthermore, there is another fundamental difference between hemal and lymph nodes which has been overlooked so far, but to which attention was directed earlier in this discussion. It was emphasized in connection with injections that, as is well known, in mature lymph nodes injected from the vascular system, the transition from the artery to the vein is a very gradual one. These injections of the vascular system present many fine arborizations, as is characteristic of the vascular system in general. In the case of hemal nodes, on the contrary, there apparently is no such gradual transition by means of capillaries, but by very wide sinuses, devoid of reticulum and having walls like capillaries. These open directly into the draining vein, and communicate with the parenchyma and indirectly with the blood spaces. Hence it is evident that in order to change a lymph into a hemal node it is not only necessary to remove the characteristic lymph sinuses and lymph vessels, but to profoundly alter the vascular system. This fact and the fact that the distribution of the blood spaces-the so-called peripheral and central sinuses of hemal nodes -which are considered comparable to the lymph sinuses in lymph nodes, have a wholly different distribution, and do not as a rule form a communicating system, is also overlooked by $\mathrm{v}$ Schumacher, who concluded that an alteration in or an obliteration of the lymphatics is all that is required to convert a lymph node into a hemal node.

Hemal nodes in which the lymphatics ended blindly in the hilus, as reported by Helly, or in the capsule, as reported by $\mathrm{v}$ Schumacher and denied by Helly, or in which all stages of partial penetration of the nodes by lymph vessels occurred, were not found. Lymphatics were either present or wholly absent in all nodes examined experimentally or microscopically; and whatever explanation or explanations it may be possible to give for the occurrence of so-called hemorrhagic lymph nodes, - the occurrence of which no one doubts- $i$. e., nodes in which blood cells are present in the lymphatic sinuses and parenchyma-it must be evi- 
dent, of course, that congestion or hemorrhage or diapedesis in an organ does not change the essential morphological identity of that organ.

Upon microscopical examination most of these apparently transitional forms were found to contain no lacunae of Weidenreich (true venous sinuses) or large blood islands or blood spaces. In addition to portions of the parenchyma which looked like splenic tissue devoid of Malpighian corpuscles, or which, on the contrary, consisted of an almost solid mass of lymphatic tissue, they contained areas in which a great deal of golden pigment, and more rarely many oxyphile cells, were present. The partly depleted nature of certain of these nodes, and especially the presence in them of much brassy pigment and the occurrence of abundant phagocytosis, gave a very peculiar appearance to a section. Because of the open character of the parenchyma, they simulated lymph nodes much more closely microscopically than hemal nodes. Since phagocytosis is a very noticeable feature in these specimens, it does not seem impossible, to me, that Lewis's [14] observations regarding the relative. frequency of phagocytosis in the spleen to that in the hemal nodes, was based on observations on this type of lymph node. This supposition gains in probability by the observations made on pathological human lymph nodes by Warthin and Meek, to the effect that the degree of pigmentation varies with the amount of hemolysis; and also by the observations of $\mathrm{v}$ Schumacher regarding the comparative infrequency of phagocytosis in hemal nodes. Meek also speaks of the occurrence of "yellow or light brown pigment, usually confined to the sinuses though rarely found in the germ centers." Meek also found that even in these pathological human nodes the reactions for free iron were very variable, and in the majority of cases not obtained, though occasionally the presence of a large amount of free iron could be established. These findings of Meek are in entire accord with what was found by the writer in intensely congested, apparently hemal nodes, found along the common iliac vessels in the carcass of a sheep which had been seriously torn in the gluteal region by dogs, and in another which died of septicaemia. The first sheep was bled to death after necrosis had set in at the site of injury, some days after having been attacked. At necropsy it was found that practically all the pelvic and prevertebral lymph nodes were hemal in color, and could probably not have been identified positively by microscopic examination alone ; yet by injections it was easily shown that they were lymph nodes in direct connection with the lumbar lymphatics and the thoracic duct. The dilated lymphatics going to these nodes were plainly visible, and were tinged with blood. It would be ridiculous, to be sure, to assume that simply because this animal had been attacked by 
a dog or dogs-and what matters it whether the attacking agent is a $\mathrm{dog}$, a disease, or an experimenter?-these lymph nodes had been converted into hemal nodes. In a second sheep similar conditions were found, and similar results obtained.

In addition to small quantities of lymphatic tissue intermixed with blood and pigment, some of the apparently mixed nodes found in sheep contain extremely large connective tissue septa and trabeculae, and the walls of some of the arteries are many times the ordinary thickness. These connective tissue septa are rarely so thick and so extensive that they could be seen with the unaided eye, to divide a section of a node 4- $6 \mathrm{~mm}$. in size into more or less distinct portions. Sometimes, also, large masses of connective tissue lay here and there under the capsule, although not continuous with it. In other instances, although not evident to the unaided eye, the total amount as well as the relative proportions of the connective tissue were smaller than usual, and located mainly in the center of the node. Frequently, also small numbers of erythrocytes and lymphocytes were scattered about miscellaneously in the connective tissue septa.

The arteries with greatly thickened walls were found almost exclusively in areas very largely devoid of lymphocytes and erythrocytes. No sclerotic or atheromatous changes were seen. The intima was normal or practically so, and the thickening of the wall was due entirely to an increase in thickness of the muscular, and chiefly of the adventitial coats. Although slight variations in staining power were observed, this thickening of the wall was probably of no significance with respect to the character of the node, even if it was correlated with its functional activity.

Many of the erythrocytes scattered about in these depleted areas showed degenerative changes; but in those portions of the sections of the node which had more the appearance of hemal nodes and where they were more numerous, they were better preserved. These degenerating erythrocytes often lay in groups, which sometimes formed a more or less compact mass around leucocytes. Only small, compact masses of lymphocytes were contained in the depleted portions, but their number increased toward the denser portions of the node, until the inter-follicular areas looked not unlike splenic tissue because of the intermixture of blood and lymphocytes. Between these denser portions of parenchyma small numbers of lymphocytes were also scattered about among certain oxyphile cells and erythrocytes; and while follicles were found in the empty portions, they were common and frequently large in the non-depleted portions. In these areas the connective tissue septa were, as a rule, consider- 
ably thicker than usual, and a very coarse and imperfect reticulum was noticeable by means of the ordinary stains. It is, however, the above referred to acidophile phagocytic cells with a hyaline like protoplasm and the presence of pigment, which gave sections of some of these nodes the prominent distinguishing microscopical characteristics. These acidophile cells are occasionally so numerous and so large that they are plainly evident under low-power magnification. In contrast to the lymphocytes and erythrocytes, they are most abundant in the depleted portions, and gradually decrease in number as the more typical portions of the node are approached. In the depth of the latter they are practically absent. Though most of them are fairly circular in outline, some are quite irregular in form. In some cases this irregularity of form seemed to be due to degenerative changes, or slight lobulation; but many of them had distinct processes, and looked exactly like branched connective tissue cells, and must, I believe, be regarded as having at least partly such and a reticular origin. On some of these cells which lay isolated, processes could be seen which were in continuity with the coarser reticulum or with the cells at the border of the trabeculae. In addition to those shaped like ordinary branched connective tissue cells, others with a greatly elongated cell body with a process at each end were also found. Although but a single terminal process or a bifurcated one was seen, as a rule, other processes may, of course, have extended in other planes and directions. The nuclei of these cells are vesicular, irregularly oval in outline, fairly central in position, seldom larger than twice the size of the erythrocytes, and contain but few chromatin granules. Usually only one nucleus is present, but it is not uncommon to find polynuclear cells. The cytoplasm, which is abundant and takes an acidophile stain, is non-granular or nearly so in non-pigmented cells; but cell inclusions are very common. The latter usually have the form and appearance of laked erythrocytes, and, if external appearances are a sufficient guide, may be designated positively as such. One or two such cellular inclusions are very common, and specimens with four or more occasionally occur. While most of the cells containing erythrocytes are non-pigmented, many of those without inclusions have a protoplasm which is very densely filled with golden or brassy pigment granules. This intra-cellular pigment is not confined to the cell body, however, but is also found in some of the processes. Although the proportion of the intra- and extra-cellular pigment varies considerably in different nodes, the size of the granules is quite uniform. Special tests for iron were used repeatedly on sections from these pigmented specimens, but no positive results were obtained. It is of particular interest in this connection that similar pigment and acidophile cells undoubtedly phago- 
cytic in function, are also found in small numbers in some typical lymph nodes; and that, as far as microscopical appearances are concerned, there is a striking similarity between the sections of the latter and some of the specimens which simulate hemal nodes so closely in external and microscopical appearances.

\section{The Genesis of Intermediate Forms}

A moment's reflection will make it evident that any condition which results in congestion or hemorrhage or the accumulation of blood cells in the parenchyma or the sinuses of lymph nodes, will produce the specimens which have been responsible for much confusion. In fact many investigators frankly stated that they could not distinguish between congested or hemorrhagic lymph nodes and hemal nodes. Haberer [IO], for example, stated that he repeatedly confused human lymph nodes which were changed by sepsis, with accessory spleens macroscopically although they were found to be typical lymph nodes microscopically. Haberer also called attention to the fact that in emaciated individuals nodes are frequenly found which do not look like spleens mrcroscopically because they lack Malpighian corpuscles, but which seem to be transition forms resulting from pathological conditions. Moreover, it is probable that the changes observed in lymph nodes after splenectomy by many, if not all, the early experimenters, were of septic origin, as Foa and Schiff held, and as their own descriptions suggest. Besides, it is apparent that blood cells must be found in the sinuses of lymph nodes whenever the afferent lymphatics drain an area in which such cells can enter the lymphatic vessels, as in the case of wounds, injuries, inflammations, etc. Retterer and Lelievre [23] also showed that stasis of the lymph current results in the accumlation of blood cells in lymph nodes. Hence these authors conclude that hemolymph nodes are only lymph nodes in which there is stagnation of the lymph current. Retterer [19], who called attention to the fact that "ten years since"-thirteen years-he reported the constant presence of erythrocytes in the lymph of the dog, rabbit, and guinea-pig, says Forgeot has shown the same for ruminants. Forgeot [6] also claimed to have found nodes in the lumbar region of sheep, goats, and under the pleura and pericardium in bovines, from which blindly-ending efferent lymphatics of various forms extended and occasionally returned to the node. Retterer [19] furthermore found that bleeding* and temporary abstinence removed the blood cells from hemolymph nodes and

*Most investigators have held the contrary for bleeding. 
changed them into ordinary gray lymph nodes; while prolonged abstinence, on the contrary, resulted in the accumulation of erythrocytes in lymph nodes.

From these considerations it is evident that many morbid and abnormal conditions can cause an accumulation of blood cells in the parenchyma and sinuses of lymph nodes, and that blood cells are probably constantly present in the lymph of many, if not of all mammals. From observations made especially on dogs the writer is also convinced that there often is a retrogression, or better a diffusion, of blood from the large veins into the large lymphatic trunks at points of juncture, which can convert many of the bronchial and mediastinal lymph nodes into so-called hemolymph nodes. $\dagger^{\dagger}$ The distance to which this reflow or intermixture of venous blood-or suspensions and solutions injected into the veins-can extend into the lymphatics is truly remarkable, and is discussed more fully in an article on the hemal nodes of dogs, cats, etc. A similar retrograde flow of chyle was noticed in several instances from the large abdominal lymphatics to the external iliac trunks almost up to the inguinal ligament in dogs. It should also be recalled in this connection that unusual lymphatico-venous connections may rarely be a factor in the production of hemorrhagic lymph nodes. It is not my aim to open an old controversy regarding lymphatico-venous communications, but the evidences recently brought forward by Huntington $[\mathrm{I} I a]$ in Macropus rufus, by McClure and Silvester [16] for primates, carnivora, rodents, ungi1lates and marsupials, by Silvester [26] for the monkey, and by Baum [I] for bovines, seem to confirm, in a measure, the early observations of Wutzer, Nuhn, Petrel, Kaaw, Kulmus, Lohmann, Fauth, J. Müller, Panizza, Meckel Sr. and Jr., Steno, Nuck, Pequet and others on man and animals which a partly justified skepticism has so far obstinately refused to accept. The writer has not much confirmatory evidence, but it is clear that where a lymph node is intercalated in a lymphatic circuit, in such a way as to have a double communication with the veins, retrograde diffusion of blood from the peripheral vein through a short efferent lymphatic into the node can easily convert all nodes lying more centrally on the lymphatic circuit into reddened lymph nodes, because of an intermixture of blood and lymph in the sinuses of the more centrally placed lymph nodes. Such a case was actually observed by the writer in a lamb in the case of an axillary lymph node on each side.

†Although Retterer (Comptes Rendus de l'Assoc. des Anat., Lyon, 19or) rejects such an explanation in referring to a similar explanation made by Thomas Bartholin, I am certain that a reflow or diffusion of blood from the large veins into the lymphatics occasionally occurs. 
Another explanation for the occurrence of reddened lymph nodes lies in the old observation that such a wide and direct open communication between the afferent and efferent lymphatics of a node may exist directly through the peripheral sinus, that the active lymph current is largely, even if not wholly, limited to the latter. Under such circumsances there would be a slow lymph current in the interior of the node, with consequent accumulation of blood cells as a result of stasis. That nodes with such circulatory conditions exist is beyond question, for the varying rate with which suspensions of India ink traverse a node is quite striking. Were it not for the existence of such large peripheral sinuses, a great deal more difficulty would also be experienced in injecting a series of successive nodes from the most peripheral one, and of accounting for the ease with which the thoracic duct, even up to its entrance into the vein, can occasionally be injected from the pad of the foot in the cat. In several instances this was accomplished with but a small fraction of a barrelful of India ink contained in a hypodermic syringe of $21 / 2 \mathrm{cc}$. volume. These observations confirm the inferences of $v$ Frey and Donders, and also the observations of Richter in the pig.

In looking about for an explanation for the reddening of lymph nodes and the presence of blood in the sinuses, Vincent [29] said: "I have not so far studied the blood supply to these glands by means of injections, nor have I succeeded in finding the blood vessels in direct communication with the 'lymph' sinuses of the gland; but from the large number of red corpuscles sometimes found in them, I am convinced that there must be such communication." It will be remembered that Meckel Jr. and Sr., Lindner, Fohmann, Lauth, and, of course, Lippi, also believed in the existence of such communications, and that Lewis [13] claims to have abundantly confirmed such occurrences by observation. While making thousands of injections of lymph nodes, no evidence for the existence of such communications, whose accidental existence is therefore not denied, was obtained in the sheep. However, in young cats, in which the mesenteric lymph nodes are very tender, both veins and lymphatics were not infrequently injected by puncture from a node. In most instances the lymphatics were injected first, and then the veins. Moreover, in guinea-pigs such results are far easier to obtain, and not infrequently the injection of veins and lymphatics is practically simultaneous. Nevertheless, a little experimentation proves conclusively that these results are obtained only because the tender nodes are distended by the injected mass, and hence disrupted by it, and by the relatively large needle or capillary tube used for purpose of puncture injections. Injections of these mesen- 
teric nodes from the periphery never resulted in injection of the veins, even when the efferent lymphatic trunk was clamped.

From all these considerations it is evident that there is no lack of abundant explanation for the occurrence of erythrocytes in the sinuses and parenchyma of lymph node-much less for the reddening-entirely aside from questions of disease, the assumption of intra-nodal lymphaticovenous communications, or the formation of erythrocytes within lymph nodes, under normal conditions.

\section{CLASSIFication}

Saltykow [25] and Retterer, working with human material, pronounced against the specific character of the hemolymph nodes. Their opinion was confirmed later by Vincent and HHarrison [28], who, from their work on bovines and sheep, concluded that hemolymph glands are modified lymph glands, and that they develop from them. A similar position is taken by Meek [I7], who declared that "it seems unreasonable that human 'hemolymph' glands should be classed as a separate category." If these conclusions are correct it is evident, of course, that what have been repeatedly described in man as hemolymph nodes are nothing but modified lymph nodes. However, Warthin not only distinguished lymph and hemolymph nodes in man, but described three classes in the latter and also differentiated spleno- and marrow lymph nodes, both of which classes were said to be in connection with the lymphatic system. In spite of these facts, Warthin nevertheless declared that only the second class, or marrow lymph glands, were organs sui generis. Warthin further stated that the long axis of marrow lymph nodes usually lay parallel to the adjacent vessel. How it is possible to regard some and not other hemal nodes as organs sui generis while maintaining the occurrence of transition and combination forms, is not clear to the writer. Nor is it clear how those who reported the occurrence of lymphatics in hemal nodes satisfied themselves that the assumed nodes really were hemal nodes, or that the lymph spaces really were lymphatic spaces, without actually demonstrating their relation to the lymphatic system. In contrast to Warthin, v Schumacher, who also observed all manner of transition forms between lymph and hemolymph nodes as far as the relations of the lymphatics are concerned, regarded the latter as rudimentary or undeveloped lymph nodes, and hence consistently pronounced against their being organs sui generis. v Schumacher distinguished only two kinds of lymph nodes, viz. (I) those with, and (2) those without lymph vessels, both of which classes may contain erythrocytes in the sinuses and parenchyma, and believed in a transform- 
ation of group I into group 2, and also regarded a retransformation probable.

Baum [I] recognized two classes of hemolymph nodes: those without lymphatics, which he designated lymphoid hemal nodes; and those with afferent and efferent lymphatics, or lymphatic hemal nodes.

Weidenreich was the first to demonstrate experimentally that the socalled hemolymph nodes in the sheep are wholly independent of the lymphatic system, thus, in a measure, justifying Drummond's supposition that they are organs sui generis. This statement of Weidenreich has been abundantly confirmed by the present investigation. Consequently there would seem to be no need for any more than two classes of lymphoid organs-lymph and hemal nodes. That not all hemal nodes varying in structure quantitatively can or should be classified separately is evident, of course; and such an elaborate classification as suggested by Lewis [13] and Warthin [ 32 and 35] is unwarranted, confusing, and certainly unscientific. The many structural variations in hemal nodes to which attention has been directed, no more justify separate classification than would the manifold variations in external form of such an organ as the liver, for example.

Neither the term hemal nor hemolymph node is wholly satisfactory or an appropriate one, however, for not all hemal nodes have an appreciable quantity of blood in the parenchyma; although they are intercalated in the vascular, and not merely in the venous system, as has been variously stated. Lymph nodes, on the contrary, are of course not, as the term would imply, only in relation with the lymphatic system. Hence lymph nodes are virtually the only true hemolymph nodes, for they alone have both lymphatic and vascular circulations wholly independent of each other. The term hemoadenoid would be clumsy and equally confusing as hemolymph; and while the term splenic is undoubtedly the most preferable and proper, in spite of the absence of Malpighian corpuscles in almost all hemal nodes of the sheep, the writer does not feel justified in introducing another term and thus adding to the confusion which already exists. Hence the retention of the term hemal node seemed commendable.

A subdivision of hemal nodes into active and inactive, while emphasizing certain prominent physiological differences, would not be exclusive either, for there probably are very few nodes in which functional processes are wholly in abeyance, even when the nodes are being rapidly depleted of lymphocytes and converted into a sac of blood. Moreover, we know but little regarding their origin, function and final fate. It is evident, of course, that in the case of depleted nodes, poliferation may nevertheless 
be exceedingly active, even while the node is depleted rapidly. Hence such a node might really be in a state of regeneration and of hyperactivity, while appearing exhausted and depleted and hence inactive. But the most obvious objection to a physiological classification of hemal nodes lies in the fact that all manner of structurally transitional forms-i. e., active and inactive-occur if a microscopical examination of uninjected specimens is to form the criterion. Hence in the present state of our knowledge-or, better, ignorance-all attempts to subdivide hemal nodes into a number of definite classes must, it seems, remain entirely futile and wholly unjustifiable from all standpoints, even if some time ago both Lewis and Warthin stated that certain classes of hemal glands were limited to certain species.

\section{FunCtions}

Clarkson, working on the horse, sheep and pig; and some of the earliest observers, and very recently also Meek [I7], working on the pig, thought that hemal nodes were the seat of formation of erythrocytes as well as of leucocytes. Robertson, $e$. $g$., strangely enough, thought that the nuclei of the large multi-nucleated leucocytes became erythrocytes; while Meek, writing about conditions found in the hemal nodes of the pig, says: "Of special interest are certain small islets of cells which occur in the midst of the blood in the sinuses. They are sharply defined from the surrounding red blood corpuscles, and are formed from aggregations of various types of blood cells. One such focus will contain, perhaps, fifty closely-packed normoblasts, another a clump of myelocytes, neutrophylic in granulation, while yet others are made up of aggregations of polymorphonuclear cells. Mitotic figures may be seen in the cells of these islets." . . . "The above appearances would seem to suggest that a part at least of the function of these glands in the pig is concerned with the formation of blood cells, red and white; and they are described at some length, as they differ materially from the conditions found in any human hemolymph glands examined." These observations of Meek are unique, for, as emphasized by Drummond [5], the stages in the formation of erythrocytes had not been observed in developing nodes even. However, Drummond too believed that hemal nodes exercised some function in connection with erythrocytes, and suggested that this function might be a cyclical one. This conclusion of Drummond was based on the great variability in cellular content; which variations, within the same or different species, he believed to be due to varying rates of blood cell destruction. Drummond further thought that the rate of destruction of erythrocytes within the individual node or species, was dependent upon the num- 
ber of such nodes present. Warthin [33], who held that the formation of erythrocytes undoubtedly occurred in disease, also suggested a cyclical activity, and added that "the appearances (in disease in man) often suggest a transformation of adipose tissue into lymphoid tissue, and the possibility of a physiological rotation of the two forms of tissue." $v$ Schumacher thought it possible that individual erythrocytes are formed in the sheep, but regarded such an origin as a very subsidiary one. He found phagocytosis by reticulum cells and a fragmentation of erythrocytes in the phagocytes in some nodes, but saw few pigment cells. An extracellular fragmentation or degeneration of erythrocytes, as observed by Weidenreich, is denied by $\mathrm{v}$ Schumacher,- a denial wholly at variance with my own observations.

That the destruction of erythrocytes-both by extra- and intracellular disintegration and hemolysis-and the formation of leucocytes, occur within hemal nodes, is undoubted. That these processes vary extraordinarily in degree within different nodes of the same individual and species, as well as in those of different species, is also evident; and while I fully realize that it is rather venturesome and often quite futile to draw conclusions regarding function from a purely morphological basis, yet it seems to me that the supposed function of "blood destruction" has been wholly over-emphasized. Moreover, it might pertinently be suggested that it is, after all, not "blood destruction," but mainly destruction of erythrocytes, which is apparently so prominent a characteristic of some hemal nodes. Nevertheless, since so many hemal nodes contain so very little blood, even when practically entirely depleted of lymphatic tissue, it is highly improbable that destruction of erythrocytes is the chief or even as important a function of hemal nodes as would seem to be the case upon cursory examination. For even if destruction of erythrocytes, be it by phagocytosis or by erythrolysis associated or unassociated by cytorrhexis, is the chief function of hemal nodes, it is evident, of course, that these processes must in all probability be due, and solely due, to some activity on part of the parenchyma of the hemal node. Hence even if this destruction within the node were due in part to the production of some lysin, one might reasonably expect the quantity of lymphatic tissue to be considerable, or proliferation of lymphocytes most active, in nodes containing comparatively large quantities of blood. This is, however, not the case; for, as is evident, the quantity of lymphatic tissue must of necessity vary inversely with the quantity of contained blood, and it is only rarely that many follicles are found in depleted nodes or in any hemal node which contains much blood. And even when this is the case and rapid proliferation of lymphocytes occurs, this very activity would then defeat 
the main object for which these nodes are supposed to exist-viz., blood destruction. For just in proportion as the hemal node became more able to destroy blood, less of the latter would be able to stay in the node, since the more lymphatic tissue there is, the less blood can be accommodated in the parenchyma of the node. And it is, of course, in the latter and not in the vascular current within the node, that the destruction of erythrocytes is believed to occur. Then, too, it is probable that the volume of flow through the node increases, up to a certain point at least, when the node is undergoing depletion as a result of loss of lymphocytes by the blood stream, and undoubtedly also as a consequence of the exercise of the supposedly specific functions of the node in this connection. Consequently, the more rapid the flow and the larger the quantity of blood that can tarry within the node, the smaller the power of the node will be to perform the very task for which it is supposed to exist. That is, just in proportion as the need for the exercise of their function of blood destruction increased, the nodes necessarily would become progressively less competent to fulfill it. Hence rapid self-destruction would seem to be the necessary result of the exercise of a supposedly normal physiological activity. To be sure, this is the ultimate fate of every organ and organism; but it seems unlikely that organs which apparently function for comparatively long periods of time, should be subjected to such rapid self-destruction when the need for their activity becomes greater. Since, moreover, the quantity of blood in some hemal nodes is so very insignificant, and since it is such an exceedingly variable one, and particularly since no signs whatever of destruction of erythrocytes can be noticed in many nodes, it is difficult indeed to regard such a function as the only or chief role that hemal nodes play in the economy of the organism. Hence for this and other more important reasons, the designation "hemolytic organs," suggested by Warthin, does not seem to be justified; and in view of the above facts it seems more probable to me that the formation of leucocytes of various types, rather than destruction of erythrocytes, is the chief function of the hemal nodes. That eosinophiles are formed in hemal nodes one can scarcely doubt, and the same is true of phagocytes. The largest of the latter, the polykaryocytes, and some megakaryocytes, could, to be sure, not easily leave the node because of their size, and probably seldom do so. Since these poly- and megakaryocytes, especially those of giant size, are so few, however, their activity, whatever it may be, is probably not a very important one, or at least not a very pronounced one.

The supposition that formative rather than destructive processes prevail in hemal nodes also receives some support from the observations of 
Warthin [35] and others to the effect that the hemal nodes-if such there be-of man are enlarged in disease, in which blood destruction is known to occur. Moreover, no one has regarded the cause of the blood destruction to lie in the enlargement of these nodes; and it would seem more probable that hyperactivity in them at such a time should, as in the case of the bone marrow, be regarded as a constructive rather than as a primarily destructive reaction or process. Then, of course, there is the possibility that hemal nodes have the same function as the spleen-and supernumerary spleens-whatever that may be.

Although certain aspects of the cellular content and a discussion of the development of hemal nodes have been reserved for a separate article, I am prompted to call attention to certain difficulties confronting those who conclude that hemal nodes are only modified lymph nodes which may again become such and hence cease to exist. From a comparative anatomical standpoint it would seem strange that this accident in development is restricted not only to certain species, and predominates in certain regions of a given species, but occurs so much more frequently in some individuals-or at some ages-of a given species. Moreover, since the panicular and subcutaneous nodes in certain regions in bovines, are always hemal and never lymphatic nodes, and since the largest regional lymph nodes are never converted into hemal nodes, the problem is complicated still further. Besides, up to the present it has not been shown that true hemal nodes in bovines and sheep become diseased when the lymph nodes do; and no one has found a single carcass in which the place occupied so frequently by scores of hemal nodes was taken by a corresponding number of somewhat unusually placed lymph nodes. The latter is a particularly pertinent consideration in view of $v$ Schumacher's conclusions and statement that hemal nodes without lymphatics are usually small ; but that the larger hemal nodes usually possess lymphatics. Moreover, since $\mathrm{v}$ Schumacher explicitly stated that there are only two kinds of lymph nodes-those with, and those without lymphatics-he evidently uses the terms hemolymph node (Blutlymphdrüsen) and lymph node synonymously. From embryological evidence in my hands since half a decade, it is also clear that hemal nodes are not in connection with the lymphatics in their early development, and that lymph sinuses do not form in them at this time. Furthermore, from the numerous observations on the carcasses of sheep of all ages, of several scores of the new-born of many foetuses, it is evident that it is absolutely impossible to demonstrate the pre-natal or early post-natal presence of a comparable number of Anlagen of hemal nodes in the lumbar sub-vertebral region. This dif- 
ficulty is apparently met by $\mathrm{v}$ Schumacher's suggestion that lymph nodes - among which he includes hemolymph nodes-probably continue to form in post-natal life.

Then there are, of course, the structural difficulties, especially those concerning the venous system, and the distribution and character of the so-called blood sinuses of hemal nodes, said to correspond to those of lymph nodes, which must be met by those who maintain a conversion of one type of node into the other. To be sure, I am fully aware that there are also difficulties and interrogations to be met by those who have been prompted to believe in the morphological identity of hemal nodes. The discussion of these will be reserved for a separate article on the hemal nodes of Bos taurus and Capra hircus. 


\section{APPENDIX}

A short summary of other articles by the writer, on the subject of hemal nodes and related structures, is appended for the convenience of those who may not have access to all of them.

I. Subcutaneous and Sub-Panicular Haemolymph Glands. Anatomical Record, vol. II, Nos. I and 2, May 1908.

Under this title a brief statement of a report given before the Association of American Anatomists in Chicago, in December 1907, was published with the proceedings of the society in the Anatomical Record, vol. II, nos. I and 2, May I908. In this report it was stated that while engaged in an investigation of the hemal nodes of the sheep in the abattoirs of Minneapolis, where bovines were being simultaneously slaugintered, my attention was directed to nodes lying in the subcutaneous fat of the trunk of carcasses of bovines. These nodes were found to vary in number, from isolated specimens to approximately a score, and varied in size from one-half to one and a half centimeters. They were oval or circular in outline, and usually flattened laterally. It was stated that "In color they vary from a bluish black to a bright red or pale pink. They are usually firm, the blood cannot be expressed from them by pressure, and injections of India ink fail to reveal any lymphatic vessels. They are most numerous in young cattle, and were found in foetuses of twentytwo or more centimeters in length. In old cattle they are generally small or absent altogether.

"Their structure is very similar to that of the haemolymph nodes of sheep, and as wide variations in structure were found to exist. Such differences in structure as exist are minor, even in the case of developing glands. In the latter the occurrence of giant cells is particularly noticeable, and, as in the case of developing haemolymph nodes of the sheep, they arise from mesenchyme.

"In carcasses showing evidences of generalized tuberculosis, no change in these nodes was noticeable.

"No relation between the size and number of these nodes and any condition, save that of age, was observed, although such a relationship very likely exists." 


\section{The Haemolymph Glands of the Sheep. Ibid.}

In this report, among other things it was stated that the earliest differentiation between the Anlagen of lymph and hemal nodes was observed in foetuses $9.8 \mathrm{~cm}$. long, and that hundreds of injections from adjacent nodes, from the surrounding tissues as well as others made from the aorta and vena cava and from large lymph vessels and nodes, proved conclusively that the hemolymph nodes of the sheep are independent of the lymphatic system and are not intercalated in the veins. The following were some of the other conclusions stated there:

I. That the reticulum is not lined by endothelium.

2. That the circulation is an open one.

3. That the peripheral sinus and blood sinuses are not in direct connection with either the venous lacunae of Weidenreich or with the arteries, save developmentally.

4. That the peripheral sinus and blood sinuses are inconstant structures, while the venous lacunae are always present, even if not evident, on cross-section of a node.

5. That the arteries communicate with the venous lacunae, and that the latter communicate with each other and with the veins.

6. That the relation of the vein or veins to the node is an exceedingly variable one, and is frequently merely a contact relationship.

7. That small veins occasionally join the haemolymph nodes by penetrating the capsule near the periphery, and that these veins are afferent veins.

8. That it is easy to distinguish a haemolymph node from a lymph node by means of injection, and that it is equally easy to distinguish a venous injection from an arterial one.

9. That pigment is rarely found in haemolymph nodes, but frequently in lymph nodes. found.

Io. That "mixed glands," i. e., true haemolymph glands, were not

II. That the haemolymph nodes of the sheep, goat, and bovines are very similar in structure.

12. That, in view of these facts, the word haemolymph as applied to these nodes in the sheep is a misnomer, and that the term haemal node, suggested by Lewis, is to be preferred. 
III. The Experimental Production of Hemolymph Nodes and AcCESSORY SpleEns. Journal of Experimental Zoology, vol. I6, I9I4.

After a critical review of the literature on the above subject, the results of a series of experiments on guinea-pigs and dogs are recorded and discussed. No hemal nodes or accessory spleens were formed as result of splenectomy in young dogs, and no hemal nodes or reddened lymph nodes were produced in guinea-pigs by the repeated injection of toxine and other substances, or by a hundred or more successive withdrawals of blood in the sheep; but that changes may be produced in lymph nodes by repeated bleeding is suggested by the studies of Smith, indicating a lowering of the resistance of erythrocytes after the withdrawal of blood. However, it is more than likely that the amount and frequency of that loss are very important factors in the determination of the character and extent of the changes in lymph nodes; a conclusion which would also seem to be amply justified by Freytag's observations.

IV. Hemal Nodes in some Carnivora and Rodents. Anatomischer Anzeiger, Bd. 45, I9I3.

An examination of a large series of cats and dogs of all ages failed to reveal any hemal nodes, other than supernumerary spleens, in these animals. Similar conclusions were also reached regarding mice, rats, guinea-pigs and rabbits, but as a result of an examination of a much smaller number of animals. The structural relation of supernumerary spleens and hemal nodes is also considered briefly, and the occurrence of mixed lymph and hemal nodes referred to. The retrogression of blood and chyle in the larger lymph vessels of the dog is reported, and its significance in the production of mixed nodes emphasized.

Errata in this article as published in the Anat. Anz.: Hemal Nodes in some Carnivora and Rodents. Studies on.Hemal Nodes, III. Anat. Anz., No. 12, Bd. 45, 1913.

P. 26I, line 8-Delete the period.

P. 263, footnote reference (2)-Read Meyer, Anat. Rec., Phila., 1914 , instead of 1913 .

P. 263, line 4-Read obtained, instead of contained.

P. 268, footnote reference (I)-Read Meyer, The Hemolymph Nodes of the Sheep. Studies on Hemal Nodes, I. University Publication, Stanford University.

P. 269, line 3-Read these species.

P. 271, reference 34-Line 2, add der Milz to the title. 
V. The Occurrence of Supernumerary Spleens in Dugs and Cats, with Observations on Corpora Libera Abdominalis. Anatomical Record, vol. 8, I9I4.

In view of the experiments of Tizzoni and other investigators of that period, and also for other reasons, it became necessary to possess reliable data regarding the occurrence of accessory spleens in dogs and cats, in connection with investigations on hemal nodes in the domestic animals. A series of careful examinations on 67 dogs and 82 cats of all ages showed that supernumerary spleens are present in 14.6 per cent of the cats, and that the number in a single animal may vary from one to approximately five hundred. The existence of peculiar pedunculated omental appendages-literally appendices epiploicae-was also reported, and the relation of these to the occurrence of corpora libera abdominalis discussed. Similarly 8.9 per cent of the dogs had supernumerary spleens, the number per animal varying from one to over eight hundred. The bearing of these facts on the results of the older experiments and on the occurrence of hemal nodes in these animals, is discussed critically. Several plates represent cross-sections and gross views of some of the specimens.

VI. Hemal Nodes in Bos taurus and Capra hircus. (In publication.)

In addition to a description of the hemal nodes of goats and bovines, special emphasis is placed on the subcutaneous and subpanicular nodes of Bos taurus, and on the development of the latter and of hemal nodes in general. 


\section{REFERENCES}

I. Baum: Können Lymphgefässe direkt in Venen einmünden? Anat. Anz., Bd. 39, I9I I. 1907.

Ia. Baum: Rote Lymphknoten. Deutsch. Tierarzt. Wochenschr.,

2. Clarkson, Arthur: Report on haemal glands. Brit. Med. Jr., vol. 2 , July 25 , I 89 I. I 896.

3. Clarkson, Arthur: A text-book on Histology. Saunders, Phil.,

4. Dayton, Hughes: Haemolymph nodes. Am. Jr. Med. Sci., vol. I3I, I904.

5. Drummond, W. B.: On the structure and function of hemolymph glands. Jr. Anat. and Phys., Lond., vol. 34, 1900.

6. Forgeot: Sur quelques particularités des ganglions hémolymphatiques des ruminants. Comptes Rendus, Assoc. Anat., Nancy, I909. Accessible in review only.

7. Forgeot: Sur quelques dispositions des ganglions hémolymphatiques des ruminants. Assoc. Française pour l'avancement des Sciences, 37e session. Clermont-Ferrand, 1908. Accessible in review only.

8. Gibbes, H.: On some structures found in the connective tissue between the renal artery and vein in the human subject. Quar. Jr. of Microscop. Sci., Lond., vol. 24, 1883 .

9. Gibbes, H.: Hemolymph glands. Am. Jr. Med. Sci., vol. Io6 (n. s.), 1893 .

Io. Haberer: Lien succenturiatus und lien accessorius. Arch. $f$. Anat. u. Phys. Anat., Abt. I9oi.

I I. Helly, Konrad: Haemolymphdrüsen. Ergeben. der Anat. u. Entwicklgsch., Bd. 12, 1912.

I $a$. Huntington: Ueber die Histogenese des lymphtischen Systems beim Säugerembryo. Anat. Anz., Ergänzhft., Bd. 37, I9Io.

12. Lewis, Thomas: The structure and function of the haemolymph glands and spleen. Internat. Monatschrift. f. Anat. u. Phys., Bd. 20 , 1902 .

I3. Lewis, Thomas: Observations upon the distribution and structure of hemolymph glands in mammalia and aves, including a preliminary note on the thymus. Jr. Anat. and Phys., Lond., vol. 38, 1904.

14. Lewis, Thomas: Further observations on the functions of the spleen and other haemolymph glands. Ibid.

I5. McCarthy, D. J.: The formation of haemolymph glands from adipose tissue in man. Jr. Med. Research, Boston, vol. 9, 1903. 
16. McClure and Silvester: A comparative study of the lymphaticvenous communications in adult mammals. Ant. Record, Phil., vol. 3 , 1909 .

I7. Meek, Q. O.: Some morbid histological changes met with in the lymphatic glands, especially in connection with the formation of haemolymph glands. Quarterly Jr. Med., Oxford, vol. 3, I9IO.

I8. Morandi and Sisto: Contribution à l'étude des glandes hémolymphatiques chez l'homme et chez quelques mammifères. Arch. ital. de Biol., vol. 35, I901.

19. Retterer: Origine du plasma et de la lymph et hématies lymphatiques. Jr. de l'Anat., T. 46, I910.

20. Retterer: Sur les circonstances dans laquelles on obtient la disparition des hématies des ganglions lymphatiques ou leur stase dans les sinus de l'organe (gland hémolymphatique). Comptes Rendus, vol. 54, 1902.

21. Retterer: Sur les modifications que détermine l'abstinence dans les ganglions lymphatiques. Ibid.

22. Retterer: Structure et fonction des ganglions lymphatiques dans l'espèce humaine. Ibid.

23. Retterer et Lelièvre: Précède simple pour voir que le ganglion lymphatique possède des hématies. Comptes Rendus Soc. Biol., T. 68, I9IO.

24. Robertson, W. F.: The prevertebral haemolymph glands. Lancet, vol. 2, Nov. 29, 1890 .

25. Saltykow: Über bluthaltige Lymphdrüsen beim Menschen. Zeitschr. f. Heilk., 1900.

26. Silvester: On the presence of permanent communications between the lymphatic and venous systems at the level of the renal veins in adult South American monkeys. Am. Jr. Anat., vol. I2, I9I I.

27. v Schumacher: Bau, Entwicklung und systematische Stellung der Blutlymphdrüsen. Archiv f. mikr. Anat., Bd. 8I, I9I2.

27a. v Schumacher: Ueber Blutlymphdrüsen. Verhandl. deutsch. Anat. Gesell. Anat. Anz., Ergänzhft. 41, I9I2.

28. Vincent and Harrison: On the hemolymph glands of some vertebrates. Jr. Anat. and Phys., Lond., vol. 31, Jan. 1897.

29. Vincent, S: On haemolymph and haemal lymphatic glands. $J r$. Phys., Lond., vol. 22, I898; Proc. Physiol. Soc., p. XL.

30. Vincent, S.: The hemolymph glands of some vertebrates. $J r$. Anat. and Phys., Lond., vol. 31, I 896-97.

3I. Warthin, A. S.: The normal histology of the human hemolymph glands. Am. Jr. Anat., vol. I, I90I.

32. Warthin, A. S.: The pathology of pernicious anemia, with special reference to changes occurring in hemolymph nodes. Amer. Jr. Med. Sci., vol. 124, 1902. 
33. Warthin, A. S.: A contribution to the normal histology and pathology of the hemolymph glands. Jr. Boston Soc. Med. Sci., vol. 5, rgor.

34. Warthin, A. S.: The changes produced in the hemolymph glands of the sheep and goat by splenectomy, hemolytic poisons and hemorrhage. Jr. Med. Research, vol. 7 (n. s.), July, I902.

35. Warthin, A. S: Are the haemolymph nodes organs sui generis? Trans. Chicago Path. Soc., vol. 5, 1902.

36. Warthin, A. S.: Pseudomelanosis of the haemolymph glands. Am. Jr. Med. Sci., vol. 128 (n. s.), 1904.

37. Weidenreich, F.: Studien über das Blut und die blutbildenden und zerstörenden Organe. Arch. f. Mikr. Anat., Bd. 65, 1904.

38. Weidenreich, F.: Ueber Blutlymphdrüsen. Anat. Anz., vol. 20, 1901 .

39. White: Hemolymph glands in domestic animals. Am.Jr. Anat., vol. 3, 1904; Proc. Ass. Am. Anat., p. VIII. 



\section{Description of Plates}

FIG. I.-A small ( $5 \mathrm{~mm}$.) oval hemal node supplied with two parallel veins whose contour suggests lymphatics. These veins gave off two branches, as indicated, and joined to form a single trunk of the usual appearance.

FIG. 2.-A node similar to that represented in fig. I, with adjacent smaller nodes with veins of similar character.

FIG. 3.-A group of small discrete hemal nodes simulating a long, tortuous single node.

FIG. 4.-Appearance of the group of nodes shown in fig. 3 as seen in longitudinal section. Right half.

FIG. 5.-Hemal node injected with India ink from the vein by puncture from an adjacent node. This node contained many exceedingly large phagocytes shown as red dots all over the section, even in the follicles. All the ink lies in the venous radicles in the parenchyma.

FIG. 6.-Section of another node injected similarly to the one in fig. 5. Some pigment is free in the parenchyma and in the follicles, but very little is found in the hemal areas.

Fig. 7.- Hemal node adjacent to the thymus from a lamb 4-5 months old. Injected with carmine gelatine from the abdominal aorta. The injection is only a partial one, because the aorta was ligated proximally to the point of injection.

FIg. 8.-Camera lucida drawing of a small hemal node from a goat. The tributary veins are shown in section at the bottom and to the right, where they communicate directly with the peripheral venous lacunae but not with the subcapsular blood space. The lacunae-true venous sinuses-which are continuous, are bounded by an endothelial wall, and successive sections illustrate the relation of the veins to them and to the subcapsular blood space very clearly.

FIG. 9.-An injected lymph node from a lamb, showing the wholly different character of the injection as compared with those in figs. 5 and 6.

FIG. I0.-A hemal node from a goat, showing a vein and an artery which pass entirely through the node. Although the vein comes in contact with the hemal areas, it opens only into the parenchyma. Note the absence of a hilus, relation of the venous lacunae-clear spaces-to the hemal areas, and the relation of the latter to each other. Camera lucida.

FIG. II.-Another section of the same node showing the artery in longitudinal section and the direct continuation of the subcapsular blood area into a peri-arterial one. Camera lucida.

FIG. I2.-Two veins tributary to the subcapstilar blood space of a hemal node from the sheep. Camera lucida.

FIG. I3.-A portion of a node injected with India ink from an adjacent node. The pigment lies in the lymphatic tissue, and has not invaded the large blood space which it surrounds. $\mathrm{x} 290$.

FIG. I4.-A cross-section of a node largely depleted of lymphatic tissue, and containing very many follicles and numerous large veins.

Note-Please view figures 6,9 and 18 with a reading glass. 
FIG. I5.-A node in which the hemal area is large and continuous, and in which the remaining lymphatic tissue is found chiefly at the periphery.

FIG. I6.-A portion of an almost empty node in which all the venous radicles or lacunae are found surrounded by lymphatic tissue. A few of these communicate directly with the large hemal area, which contains little blood and many fragments of erythrocytes. This node is subdivided more or less completely by thick connective tissue septa.

FIG. 17.-Camera lucida drawing of a node containing but little lymphatic tissue, at the periphery of which a large, almost continuous lacuna is seen.

FIG. I8.-A section of an almost depleted node, showing the characteristic distribution of the lymphatic tissue with the contained venous lacunae.

FIG. I9.-A section of a similar node. The entire absence of follicles and the profoundly modified architecture suggest that such nodes are disappearing.

FIG. 20.-A small portion of a hemal node, showing a venous lacuna opening directly into the parenchyma at the left, where the degenerating erythrocytes and a large phagocyte lie. $x$ IIO.

FIG. 21.-A large venous lacuna containing granular detritus and surrounded by hemal areas composed almost wholly of excellently preserved erythrocytes, which are everywhere separated from it by definite walls and a narrow border of lymphatic tissue. $\mathrm{x} 920$.

FIG. 22.-A partially collapsed venous lacuna, showing a definite endothelial wall on one side and a barrier of lymphatic tissue on the other, separating it from the surrounding hemal areas. $x 920$.

FIG. 23.-A rare section showing the communication of a capillary with a venous lacuna. $\mathrm{x} 750$.

FIG. 24.-A section through a process of lymphatic tissue containing a large hemal area, which projects into a large venous lacuna or sinus. There is no direct communication between the latter and the hemal area anywhere. $\mathrm{x} 630$.

FIG. 25.-A portion of a large hemal area containing abundant and coarse reticulum. In many places the reticulum fibers have no doubt been forced together. x 630 .

FIG. 26.-A portion of a node showing the accumulation of eosinophiles around the artery. Several degenerating giant cells are also seen. $x$ г 340 . р. бі.

August 25, I9I3. 
<smiles>C=CC1CC1</smiles> 

No. 6

No. 5
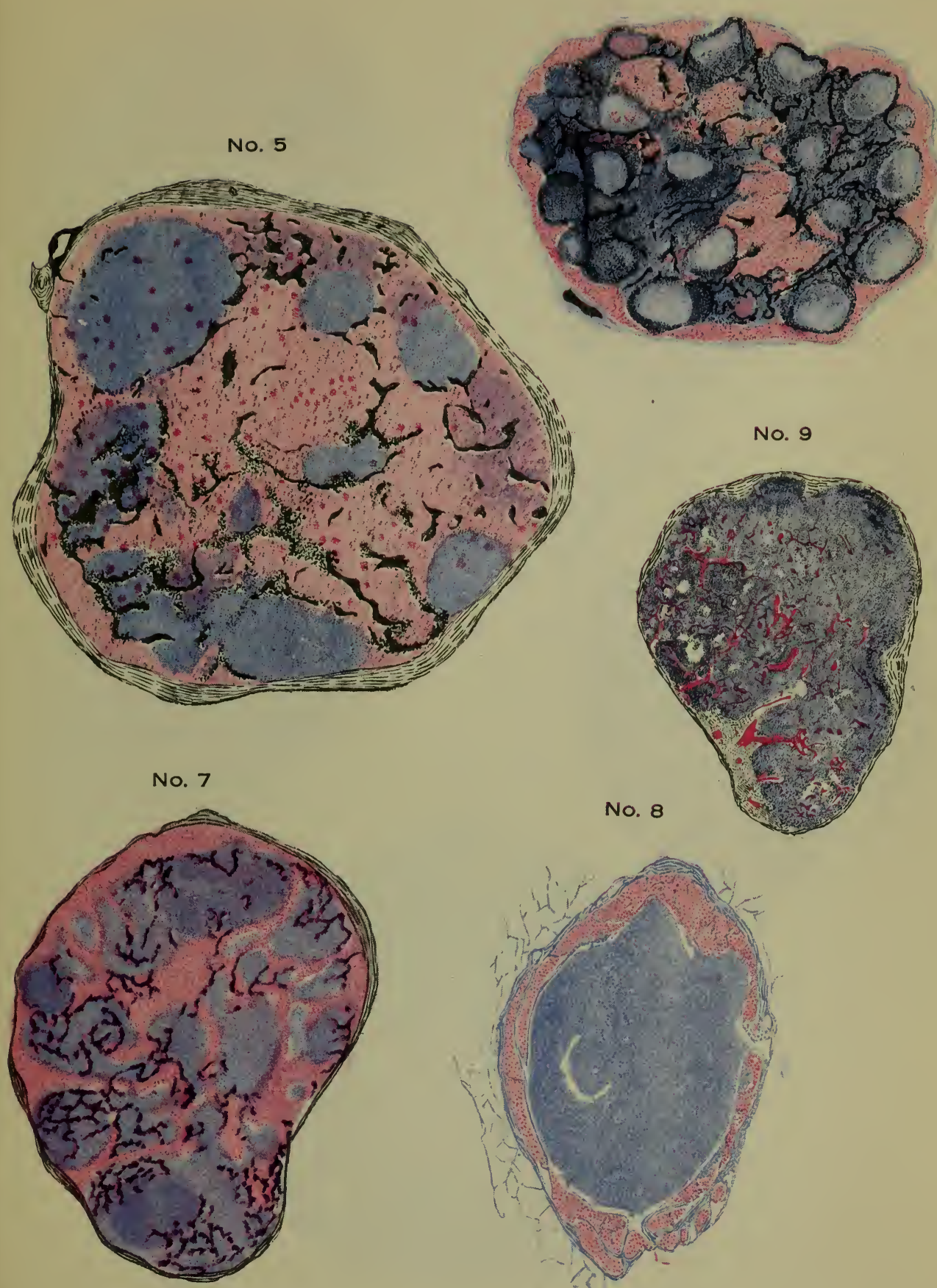

No. 8

No. 9
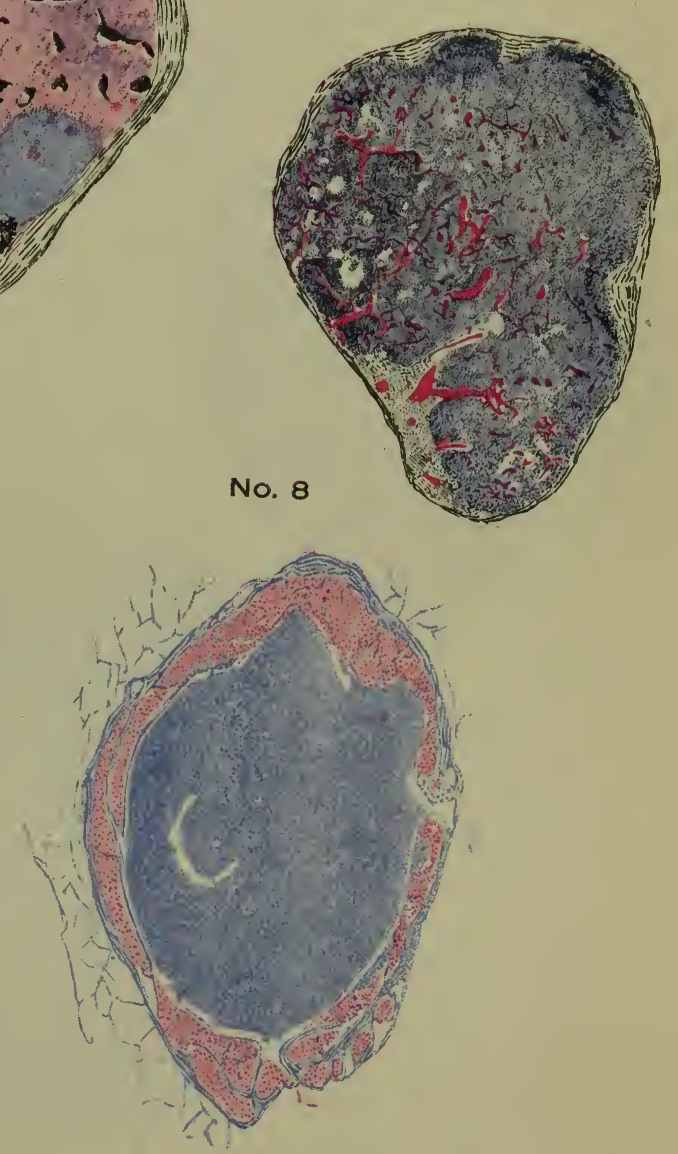

No. 10

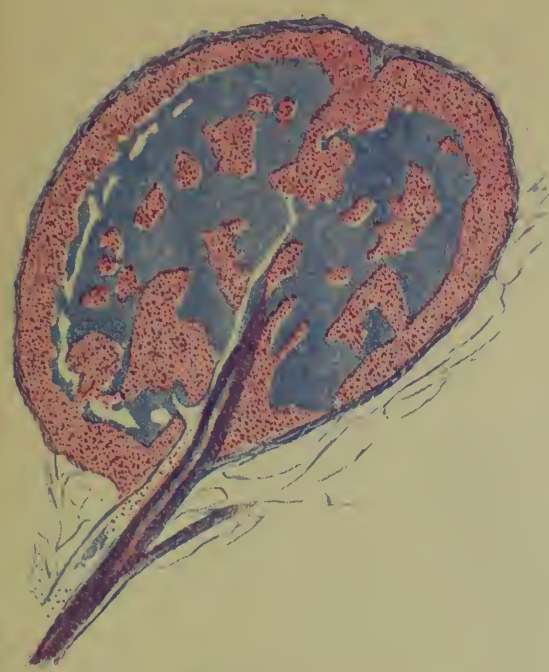

No. 12

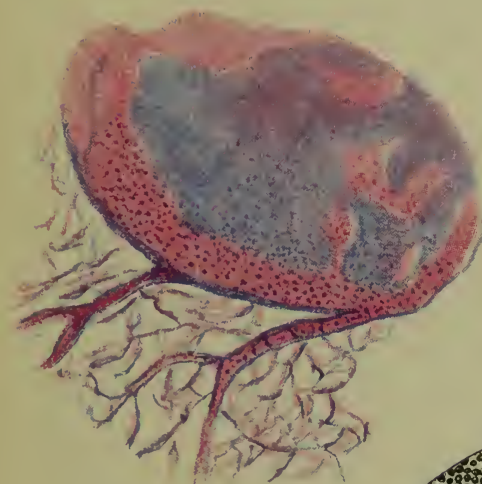

No. 11

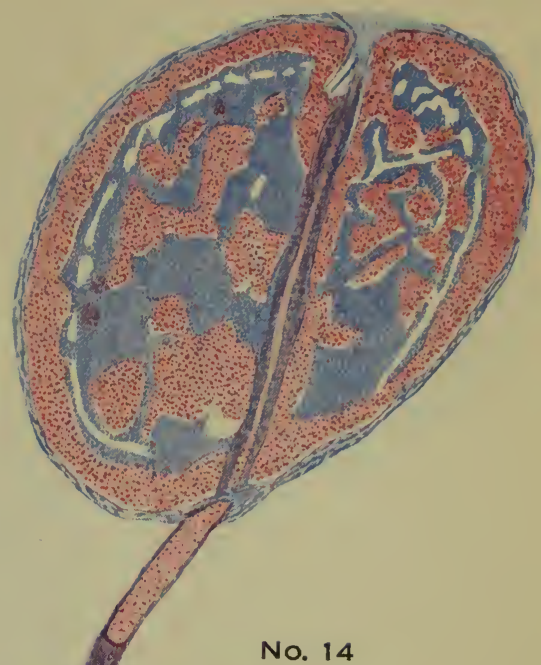

No. 14

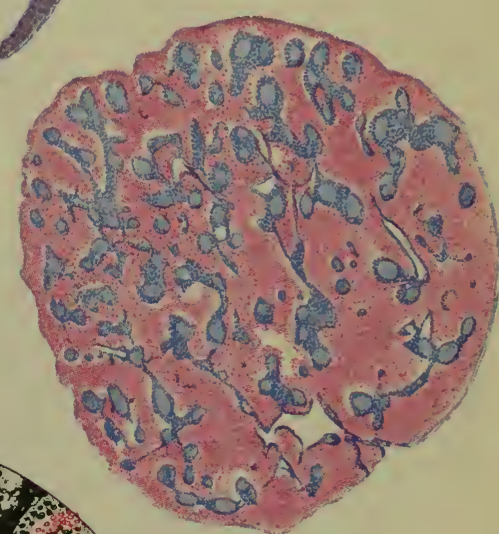

No. 13

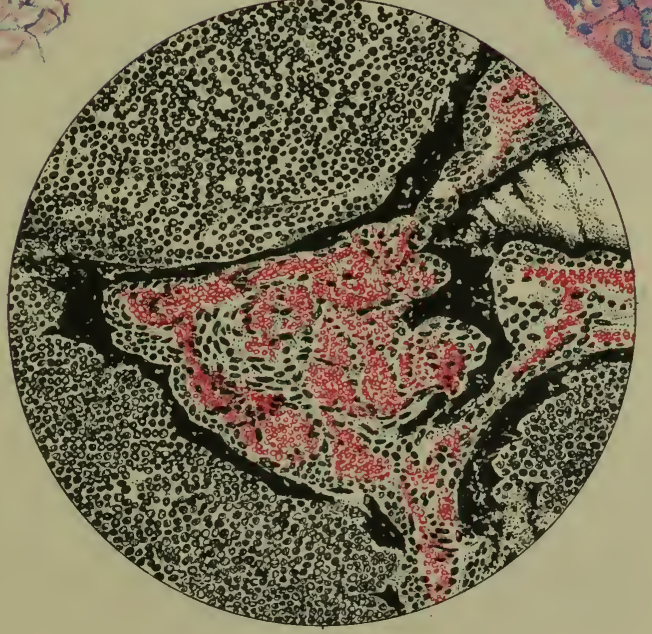


E 
No. 15

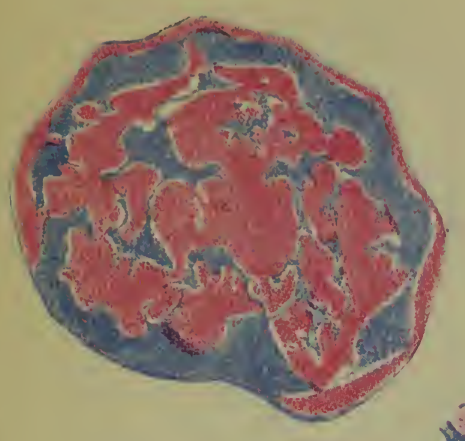

No. 18

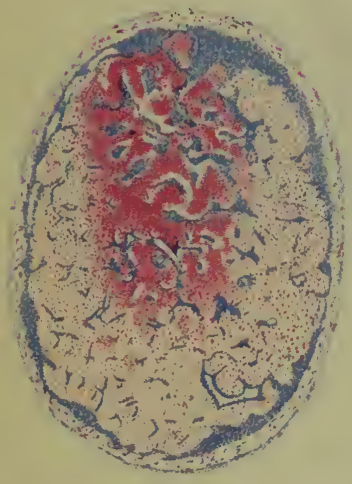

No. 17

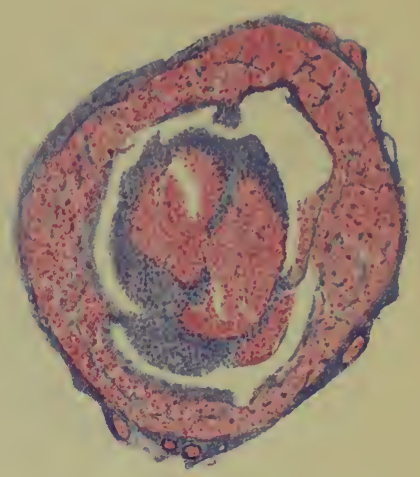

No. 19
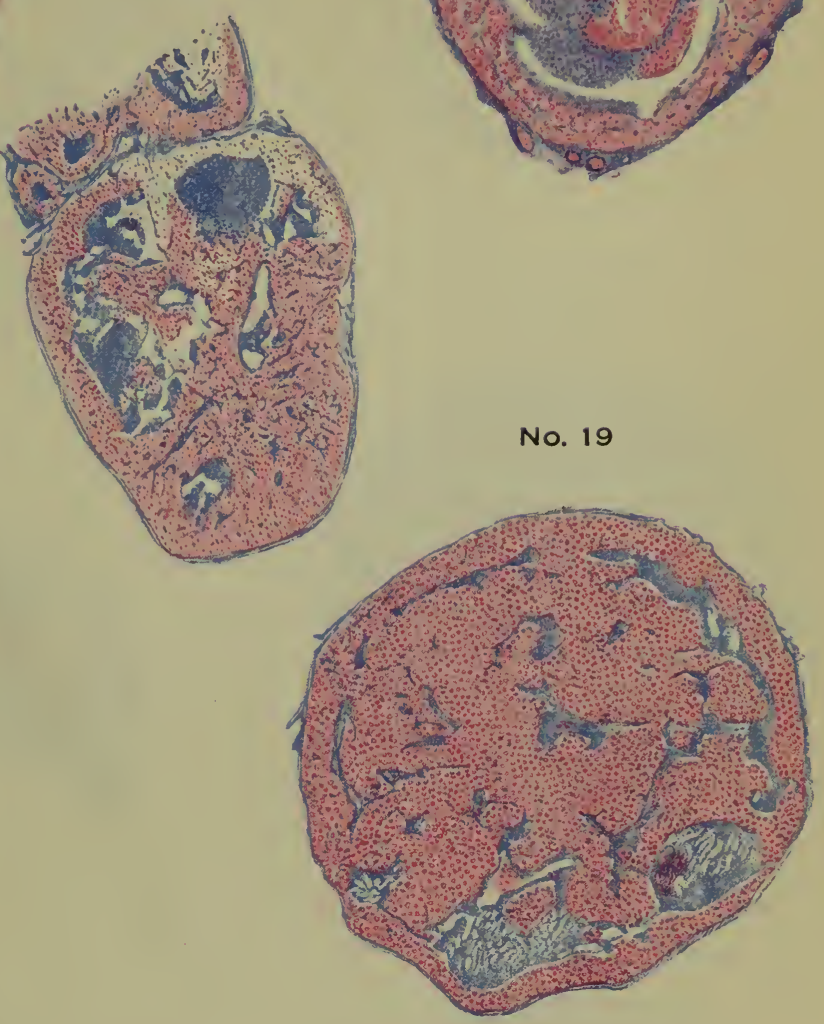

No. 20

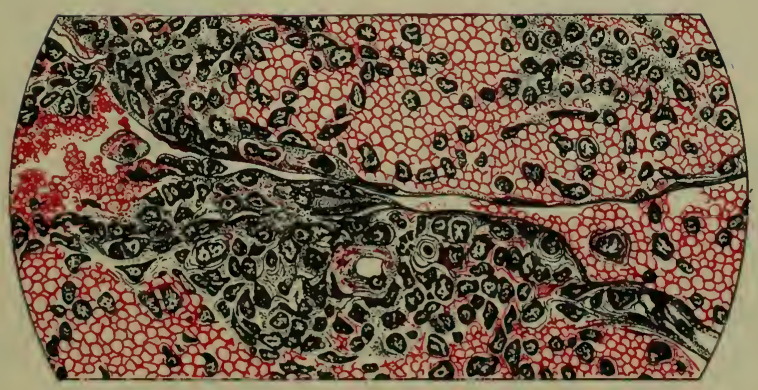



No. 21

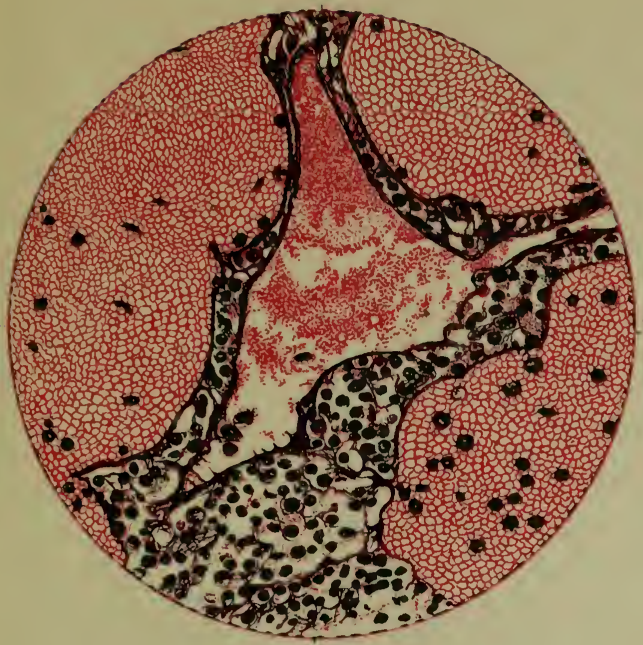

No. 23

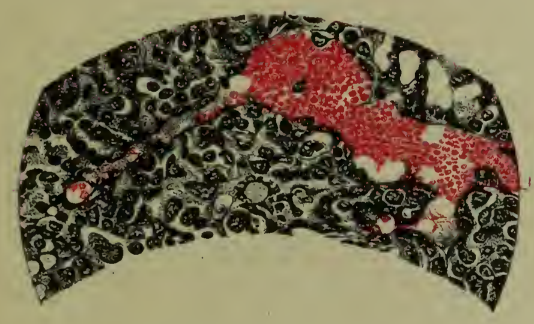

No. 25

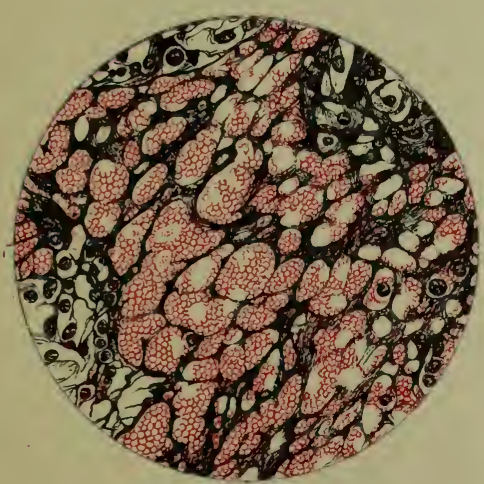

No. 22

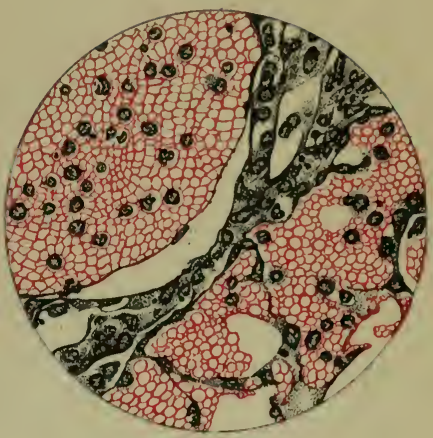

No. 24

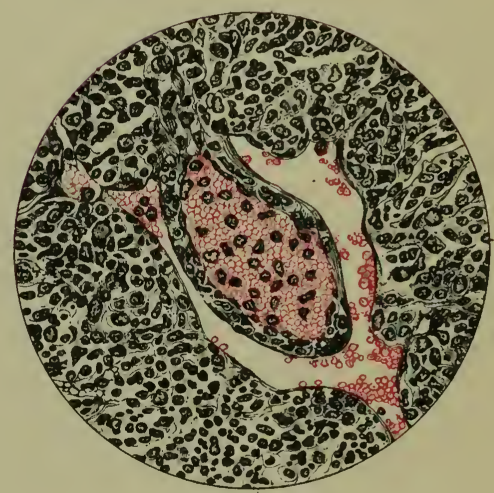

No. 26

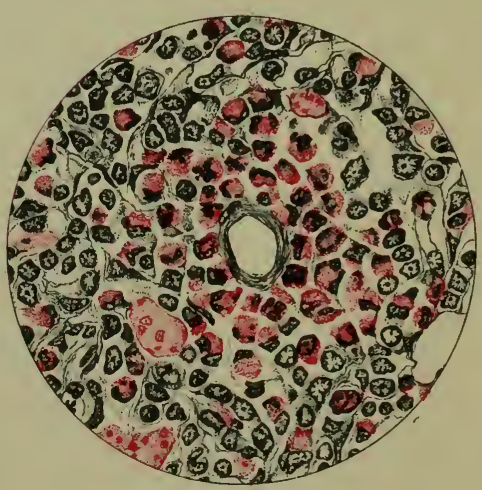






$$
4106^{*} 119
$$


The Birds of the Latin Ports. Ernest Whitney Martin, Associate Professor of Greek. 260 pp. I9I4. Price, \$1.00.

Acceleration in the Development of the Fossil Cephialopoda. James Perrin Smith, Professor of Paleontology. 30 pp., I 5 plates. 19I4. Price, 75c.

A Morphological Study of Some Members of the Genus Pallavicinia. Douglas Houghton Campbell and Florence Williams. 44 pp., 23 text figures. I9I4. Price, 50c.

The Evolution of Brazil Compared with that of Spanish and Anglo-Saxon America. Manuel de Oliveira Lima. 160 pp. 1914. Price, \$r.oo.

The Hemolymph Nodes of the Sheep. Arthur William Meyer. 74 pp., I plate, 4 colored plates. I9I4. Price, \$I.00. 
2

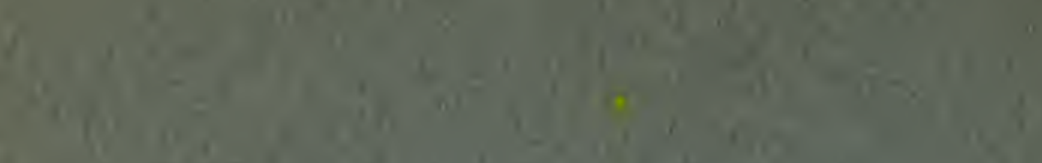

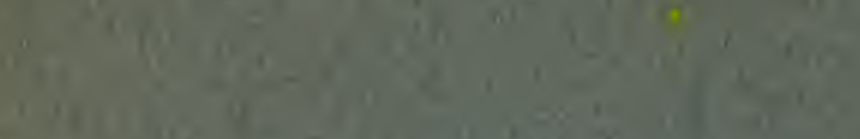

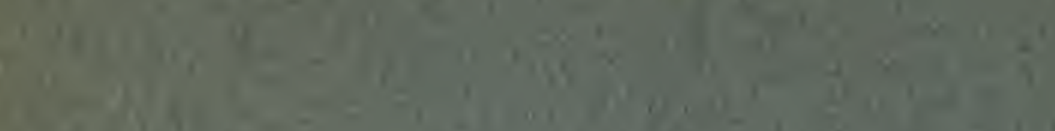

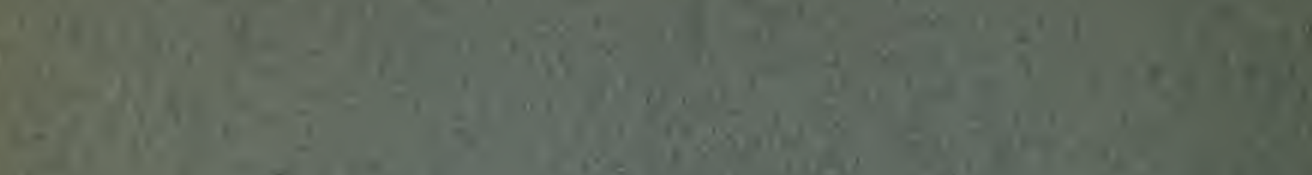

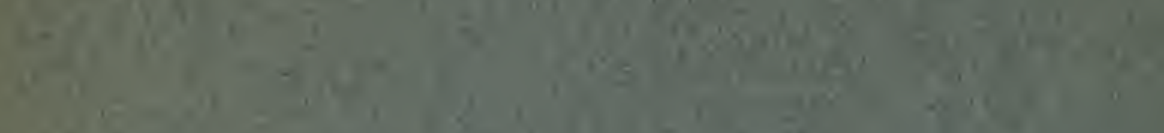

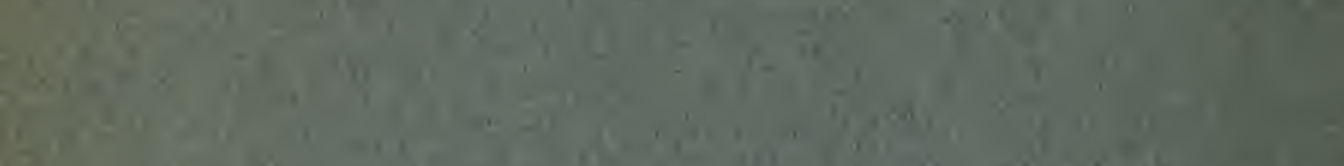

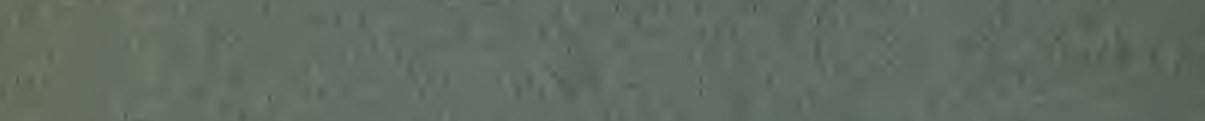

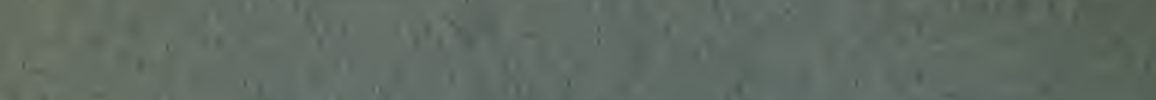



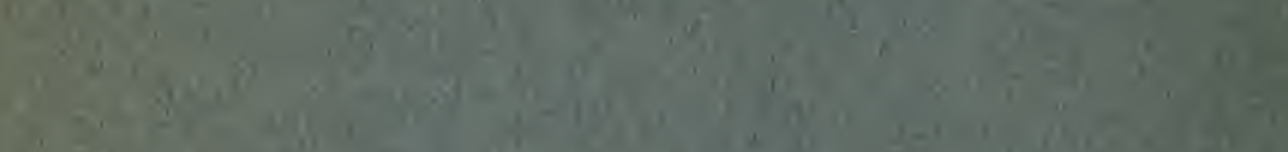

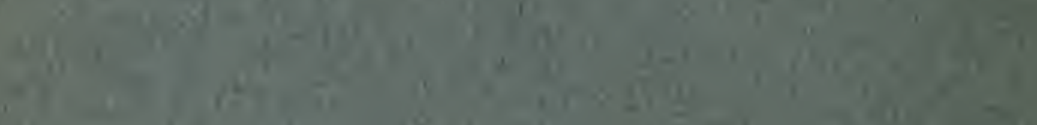

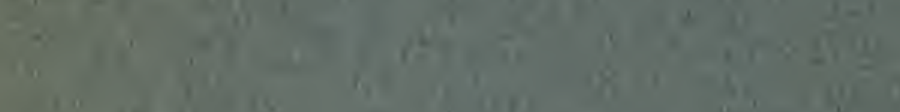

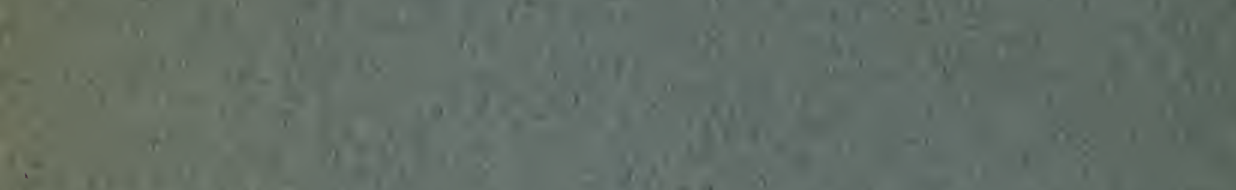

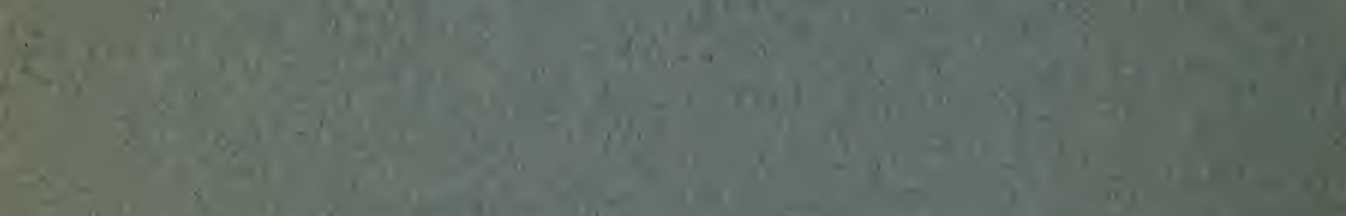

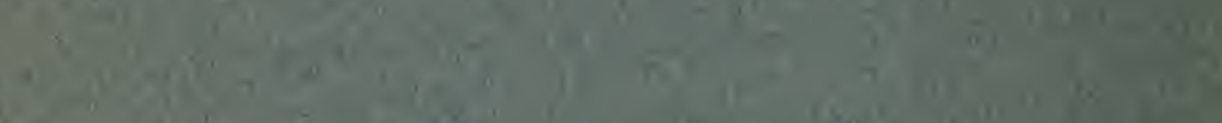

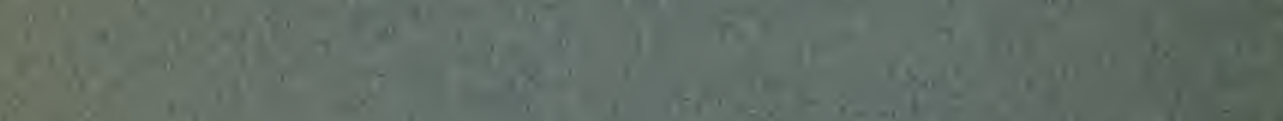

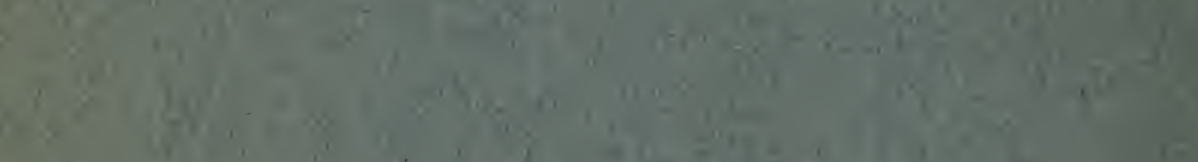

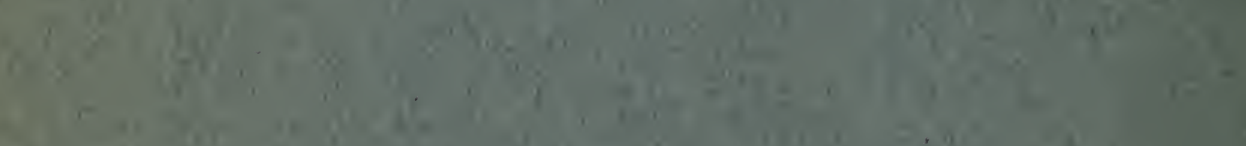

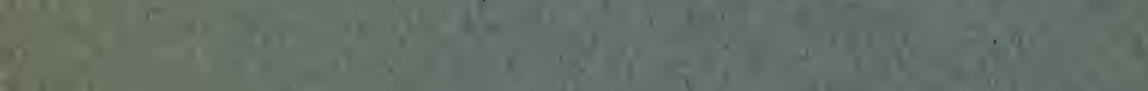

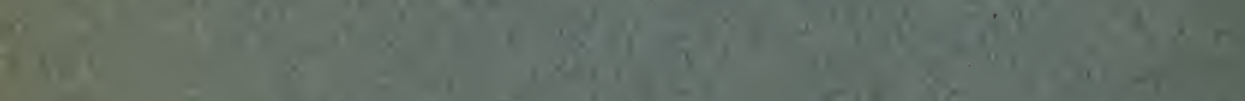

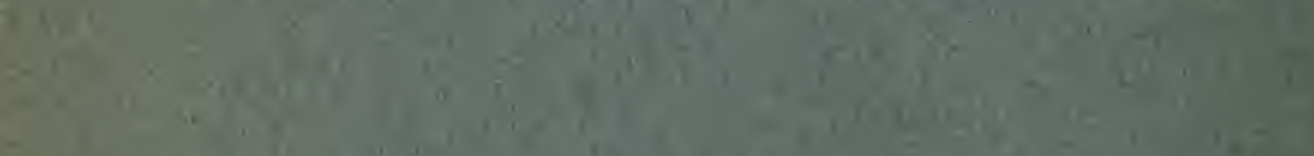

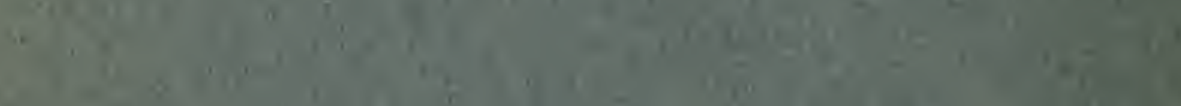



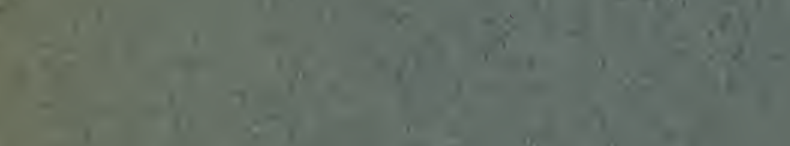

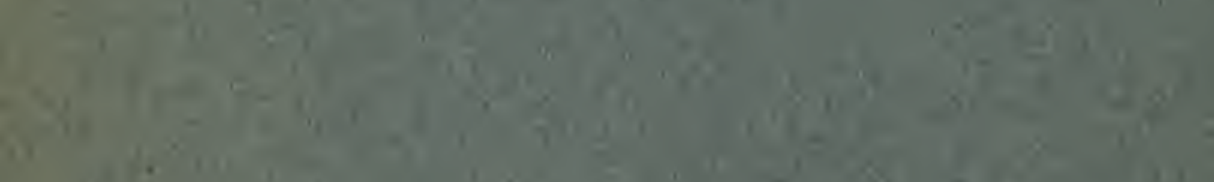
w.

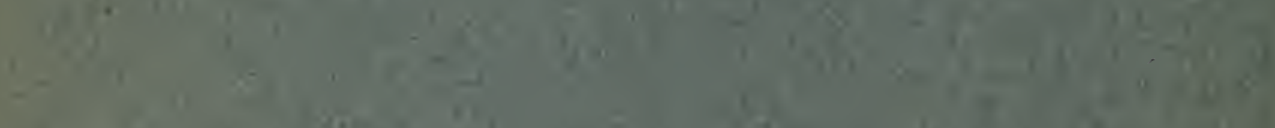

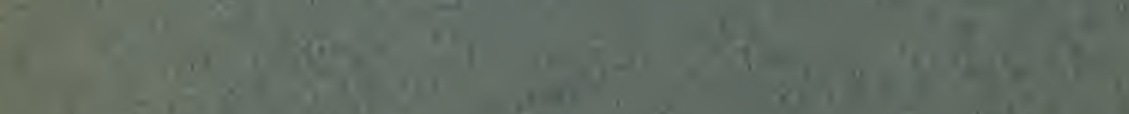






ACAIE
BOOKBINONG CO., INC.
MAY 601985
100 CAME
CHARLESTL.... . IREET MASS.




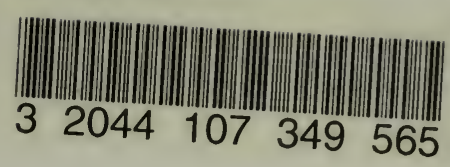


